\title{
Anti-Müllerian hormone concentration regulates activin receptor-like kinase- $2 / 3$ expression levels with opposing effects on ovarian cancer cell survival
}

\author{
MAËVA CHAUVIN $^{1}$, VÉRONIQUE GARAMBOIS ${ }^{1}$, SYLVIE CHOBLET ${ }^{2}$, PIERRE-EMMANUEL COLOMBO ${ }^{1,3}$, \\ MYRIAM CHENTOUF ${ }^{1}$, LAURENT GROS ${ }^{1}$, DAVID-PAUL DE BRAUWERE ${ }^{4}$, MARTINE DUONOR-CERUTTI ${ }^{2}$, \\ KAREN DUMAS $^{5}$, BRUNO ROBERT ${ }^{1}$, MARTA JARLIER ${ }^{3}$, PIERRE MARTINEAU ${ }^{1}$, \\ ISABELLE NAVARRO-TEULON ${ }^{1}$, DAVID PÉPIN ${ }^{6,7}$, THIERRY CHARDĖS ${ }^{1}$ and ANDRÉ PÈLEGRIN ${ }^{1}$ \\ ${ }^{1}$ IRCM, Institut de Recherche en Cancérologie de Montpellier, INSERM U1194, Université de Montpellier, \\ Institut Régional du Cancer de Montpellier, F-34298 Montpellier; ${ }^{2}$ CNRS UPS3044 Baculovirus et Thérapie, \\ F-30380 Saint-Christol-Lèz Alès; ${ }^{3}$ Institut Régional du Cancer de Montpellier, ICM, F-34298 Montpellier; \\ ${ }^{4}$ Département de Biochimie et Biologie Moléculaire, CHU de Nîmes, F-30900 Nîmes; \\ ${ }^{5}$ SurgiMAb, F-34000 Montpellier, France; ${ }^{6}$ Department of Surgery, Harvard Medical School; \\ ${ }^{7}$ Pediatric Surgical Research Laboratories, Massachusetts General Hospital, Boston, MA 02114, USA
}

Received October 12, 2020; Accepted March 11, 2021

DOI: 10.3892/ijo.2021.5223

\begin{abstract}
Anti-Müllerian hormone (AMH) type II receptor (AMHRII) and the AMH/AMHRII signaling pathway are potential therapeutic targets in ovarian carcinoma. Conversely, the role of the three AMH type I receptors (AMHRIs), namely activin receptor-like kinase (ALK)2, ALK3 and ALK6, in ovarian cancer remains to be clarified. To determine the respective roles of these three AMHRIs, the present study used four ovarian cancer cell lines (COV434-AMHRII, SKOV3-AMHRII, OVCAR8, KGN) and primary cells isolated from tumor ascites from patients with ovarian cancer. The results demonstrated that ALK2 and ALK3 may be the two main AMHRIs involved in AMH signaling at physiological endogenous and supraphysiological exogenous AMH concentrations, respectively. Supraphysiological AMH concentrations (25 $\mathrm{nM}$ recombinant AMH) were associated with apoptosis in all four cell lines and decreased clonogenic survival in COV434-AMHRII and SKOV3-AMHRII cells. These biological effects were induced via ALK3 recruitment by AMHRII, as ALK3-AMHRII dimerization was favored at increasing AMH concentrations. By contrast, ALK2 was associated with
\end{abstract}

Correspondence to: Dr André Pèlegrin, IRCM, Institut de Recherche en Cancérologie de Montpellier, INSERM U1194, Université de Montpellier, Institut Régional du Cancer de Montpellier, F-34298 Montpellier, France

E-mail: andre.pelegrin@inserm.fr

Key words: ovarian carcinoma, Müllerian inhibiting substance, anti-Müllerian hormone, activin receptor-like kinase-2, activin receptor-like kinase-3, signaling, bispecific antibody
AMHRII at physiological endogenous concentrations of AMH $(10 \mathrm{pM})$. Based on these results, tetravalent IgG1-like bispecific antibodies (BsAbs) against AMHRII and ALK2, and against AMHRII and ALK3 were designed and evaluated. In vivo, COV434-AMHRII tumor cell xenograft growth was significantly reduced in all $\mathrm{BsAb}$-treated groups compared with that in the vehicle group $(\mathrm{P}=0.018$ for $\mathrm{BsAb} 12 \mathrm{G} 4-3 \mathrm{D} 7 ; \mathrm{P}=0.001$ for all other BsAbs). However, the growth of COV434-AMHRII tumor cell xenografts was slower in mice treated with the anti-AMRII-ALK2 BsAb 12G4-2F9 compared with that in animals that received a control BsAb that targeted AMHRII and CD5 ( $\mathrm{P}=0.048)$. These results provide new insights into type I receptor specificity in AMH signaling pathways and may lead to an innovative therapeutic approach to modulate AMH signaling using anti-AMHRII/anti-AMHRI BsAbs.

\section{Introduction}

Anti-Müllerian hormone (AMH), a TGF $\beta$ family member, acts by binding to its specific receptor (AMH type II receptor; AMHRII) that recruits type I receptors (AMHRIs) activin receptor-like kinase (ALK)2, ALK3 and ALK6. AMHRI phosphorylation induces SMAD 1/5/8 phosphorylation and their migration into the nucleus where, through SMAD4, they regulate various genes depending on the target tissue $(1,2)$. Preclinical in vitro and in vivo studies and data obtained using clinical samples have demonstrated that AMHRII and the AMH/AMHRII signaling pathway are potential therapeutic targets in gynecological tumors (3-9), particularly in ovarian carcinoma (10).

The AMH/AMHRII signaling cascade can be targeted using anti-AMHRII antibodies. Among the available anti-AMHRII antibodies (11) and antibody fragments $(12,13)$, the monoclonal antibody (MAb) 12G4 and its humanized 
version (GM-102 or murlentamab) have been extensively evaluated in preclinical studies (14-17), and murlentamab is now tested in clinical trials (trial nos. NCT02978755 and NCT03799731). The mechanism of action of murlentamab involves antibody-dependent cell-mediated cytotoxicity and antibody-dependent cell phagocytosis, but no or low apoptosis depending on the model, suggesting that its efficacy is not directly related to the AMH signaling pathway $(14,15)$.

To understand why the AMH signaling pathway is not implicated in the underlying mechanisms of the effects of murlentamab, the present study aimed to analyze the role of the three AMHRIs (ALK2, ALK3 and ALK6) in ovarian carcinoma cell lines and primary carcinoma cells isolated from ascites samples of patients with ovarian carcinoma. Although the roles of ALK2, ALK3 and ALK6 have been studied in several cell types during development and in other physiological conditions (18-24), limited data are available on their roles in cancer. Basal et al (25) have demonstrated that AMHRII, ALK2, ALK3 and ALK6 are expressed in epithelial ovarian cancer specimens, but have not assessed their functions.

The results of the present study demonstrated that ALK2 and ALK3 were the two main AMHRIs implicated in AMH signaling in four ovarian cancer cell lines, and that their role was regulated by AMH concentration. Specifically, in the presence of supraphysiological concentrations of AMH $(25 \mathrm{nM}$ recombinant AMH), ALK3 was recruited, heterodimerized with AMHRII, and induced apoptotic effects. Conversely, at physiological endogenous AMH concentration (10 pM), AMH promoted cancer cell viability through ALK2 recruitment. Therefore, bispecific antibodies (BsAb) against AMHRII and ALK2, and against AMHRII and ALK3 were designed and evaluated. The results demonstrated that the anti-AMRII-ALK2 BsAb 12G4-2F9 reduced the growth of COV434-AMHRII tumor cell xenografts in vivo. Taken together, these results may provide a deeper understanding of the AMH signaling pathways and may lead to an innovative therapeutic approach to modulate AMH signaling using anti-AMHRII/AMHRI BsAbs.

\section{Materials and methods}

AMH production and assay. Active recombinant $\mathrm{AMH}$ (LR-AMH) $(9,26)$ was produced in CHO cells (Evitria AG) using proprietary media and culture conditions according to the WO2014/164891 patent (27) (Fig. S1). LR-AMH is a full-length protein that is completely cleaved, thus combining efficiency and stability $(26,28)$. It contains the 24AA leader sequence of albumin instead of the AMH leader sequence to increase production and secretion, and the RARR/S furin/kex2 consensus site instead of the native AMH RAQR/S sequence at position 423-428 to improve cleavage. AMH was quantified using the Elecsys ${ }^{\circledR}$ AMH PLUS kit (Roche Diagnostics). For western blot analysis, recombinant AMH commercialized by Origen (cat. no. TP308397) was used as the control AMH with an anti-AMH antibody (cat. no. ab84952; Abcam) that recognizes the $\mathrm{C}$-terminal domain. All experiments involving LR-AMH were performed in culture medium containing $1 \%$ fetal bovine serum (FBS; Gibco; Thermo Fisher Scientific, Inc.) as bovine AMH can signal through human AMHRII (29). In these experimental conditions, endogenous AMH concentration in fresh medium ranged between 5 and $10 \mathrm{pM}$.
Selection of anti-ALK2 and anti-ALK3 single-chain variable fragments (scFvs). Anti-ALK2 and anti-ALK3 scFvs were isolated from the human scFv phage display library Husc I $(30,31)$ by three successive panning rounds using an ECD-Fc construct (cat. no. 637-AR-100; R\&D Systems, Inc.) for ALK2 and an ECD-Fc (cat. no. 2406-BR-100; R\&D Systems, Inc.) or an ECD-Poly-His (cat.no. 10446-H08H; SinoBiological, Inc.) construct for ALK3. Two scFv antibodies were selected for each target according to the following criteria: i) Their binding to the receptor in ELISA; ii) their variable peptide sequence to target different epitopes; and iii) the number of potential glycosylation sites present in their sequences to limit the need for mutagenesis. All potential glycosylation sites in the heavy chain variable domain $(\mathrm{VH})$ and light chain variable domain (VL) of the selected ScFv antibodies were suppressed by site-directed mutagenesis (Genewiz, Inc.): The $\mathrm{VH}$ threonine 75 (Kabat numbering) was reversed to the germline lysine, whereas serine to alanine mutations were performed in the complementarity-determining region Asn-x-Ser motifs (1, 1 and 4 for 2C1, 2F9 and 3D7, respectively) to avoid binding inhibition due to $\mathrm{N}$-glycosylation.

BsAb constructs. A generic platform of tetravalent IgG1-like BsAbs was used $(32,33)$. As described in our previous study (32), BsAb synthesis requires the production of one fused heavy chain and two free light chains. The fused heavy chain contained, from the $\mathrm{N}$ - to the $\mathrm{C}$ - terminus, the $\mathrm{VH} /$ heavy chain constant domain $(\mathrm{CH}) 1$ domain of the anti-AMHRII MAb 12G4 (11) in position 2 (Fig. S2), the VH/CH1 domain of an anti-AMHRI antibody (anti-ALK2 or ALK3 Mab) in position 1, and a human IgG1 Fc domain, as well as two free light chains, namely the light chains of the anti-AMHRII and anti-AMHRI MAbs. The fragment antigen binding (Fab) sequences from the anti-AMHRII MAb were inserted in position 2 of each BsAb construct (the furthest away from the Fc fragment) to ensure specific binding to their target (32). The anti-ALK2 and anti-ALK3 Fab sequences were inserted in position 1 of the $\mathrm{BsAb}$ constructs, closer to the Fc fragment. To control the heavy chain/light chain ratio, two plasmids were constructed. Plasmid I was a bicistronic construct that contained, from the $5^{\prime}$ to the $3^{\prime}$ end: i) The cDNA encoding the complete sequence of anti-AMHRII MAb light chain under the control of the cytomegalovirus (CMV) promoter; ii) an internal ribosome entry site (IRES) sequence from ECMV (34); and iii) the cDNA encoding the complete fused heavy chain bearing the $\mathrm{VH} / \mathrm{CH} 1$ domain of the anti-AMHRII $\mathrm{MAb}$, the $\mathrm{VH} / \mathrm{CH} 1$ domain of the anti-ALK2 or anti-ALK3 $\mathrm{MAb}$ and the cDNA encoding the human IgG1 Fc domain. Plasmid II contained the cDNA encoding the complete sequence of the anti-AMHRI MAb light chain (anti-ALK2 or anti-ALK3 MAb) under the control of the CMV promoter. In the control BsAb that targeted only AMHRII and CD5 (anti-AMHRII-CD5), the cDNA encoding the VH and VL of the anti-human CD5 MAb 0490 (35) were inserted into plasmids I and II instead of the anti-AMHRI MAb sequences.

Antibody production. Anti-ALK2 and anti-ALK3 IgG1 and BsAbs were produced in CHO (Evitria AG) and 293T cells (ATCC ${ }^{\circledR}$ CRL-1573) For antibody production in 293T cells, the cells were cultured in $150 \mathrm{~mm}^{2}$ dishes to $70 \%$ confluence. A 1:1 
mixture of $30 \mu \mathrm{g}$ of plasmids I and II, and $240 \mu \mathrm{g}$ of the transfection agent polyethylenimine (PolyScience) was maintained at room temperature (RT) for 10 min and subsequently added to the cells for $6 \mathrm{~h}$ at $37^{\circ} \mathrm{C}$. Following incubation, the transfection medium was replaced with DMEM-F12 (Gibco; Thermo Fisher Scientific, Inc.) without FBS. After 5 days at $37^{\circ} \mathrm{C}$, the supernatant was collected by centrifugation at $300 \mathrm{x} \mathrm{g}$ for 5 min at $4^{\circ} \mathrm{C}$ and diluted (1:1) with $40 \mathrm{mM}$ sodium phosphate buffer, $\mathrm{pH} 8$, filtered through a $0.22-\mu \mathrm{m}$ filter and purified on a 1-ml protein A column for $24 \mathrm{~h}$ at $4^{\circ} \mathrm{C}$. The antibodies were eluted with glycine, $\mathrm{pH} 3$, and immediately stabilized with Tris buffer, $\mathrm{pH}$ 9. Amicon-ultra ${ }^{\circledR}$ filters (MiliporeSigma) with a cut-off of $50 \mathrm{kDa}$ were used for antibody concentration in PBS; $200 \mathrm{ml}$ cell culture provided $\sim 1 \mathrm{mg}$ of purified antibody.

ELISA assay. The half maximal effective concentration $\left(\mathrm{EC}_{50}\right)$ of the antibodies was determined by ELISA. Maxisorp nunc-immuno ${ }^{\circledR}$ plates (Thermo Fisher Scientific, Inc.) were coated with $500 \mathrm{ng} / \mathrm{ml}$ anti-HIS antibody (clone HIS-1; cat. no. A7058; Sigma-Aldrich; Merck KGaA) overnight at $4^{\circ} \mathrm{C}$ to capture the respective antigens of recombinant human ALK2 (cat. no. 10227-H08B; Sino Biological, Inc.), ALK3 (cat. no. 10446-H08H; Sino Biological, Inc.) or AMHRII (4749-MR-050; R\&D Systems, Inc.) used at $500 \mathrm{ng} / \mathrm{ml}$. The plates were subsequently washed three times with $\mathrm{PBS} / 0.01 \%$ Tween-20 and incubated with PBS/0.01\% Tween-20/2\% BSA (Sigma-Aldrich; Merck KGaA) solution for $2 \mathrm{~h}$ at RT for blocking. Following three washes with PBS/0.01\% Tween-20, the antibodies were added to a final concentration of ranging between 0.08 and $333 \mathrm{nM}$, and incubated at $37^{\circ} \mathrm{C}$ for $90 \mathrm{~min}$, followed by treatment with the anti-human $\mathrm{Fc}$ peroxidase secondary antibody (HRP-conjugated; cat. no. A0170; Sigma-Aldrich; Merck KGaA) for $30 \mathrm{~min}$ and the enzyme substrate (3,3',5,5'-tetramethylbenzidine; cat. no. 34028; Thermo Fisher Scientific, Inc.). Absorbance was read at $450 \mathrm{~nm}$ using a microplate reader after stopping the enzyme reaction with sulfuric acid.

Cell lines. The human COV434 (sex cord stromal tumor) $(36,37)$ and KGN (granulosa cell tumor) (38) cell lines were kind gifts from Dr. Schrier (Department of Clinical Oncology, Leiden University Medical Center, Leiden, Netherlands) and Dr Yanase (Kyushu University, Fukuoka, Japan), respectively. The SKOV3 cell line (high grade serous ovarian cancer) was obtained from ATCC $\left(\right.$ ATCC $^{\circledR}$ HTB-77), and the NIH-OVCAR8 cell line (high grade serous ovarian cancer) was obtained from the Division of Cancer Treatment and Diagnosis, NCI, Frederick, MD, USA. Cells were cultured in DMEM:F12 medium without phenol red containing $10 \%$ heat-inactivated FBS. COV434-AMHRII and SKOV3-AMHRII cells were supplemented with $0.33 \mathrm{mg} / \mathrm{ml}$ geneticin (cat. no. ant-gn-1; InvivoGen). Cells were cultured at $37^{\circ} \mathrm{C}$ in a humidified atmosphere with $5 \% \mathrm{CO}_{2}$, and the medium was replaced twice per week. Cells were harvested with $0.5 \mathrm{mg} / \mathrm{ml}$ trypsin and $0.2 \mathrm{mg} / \mathrm{ml}$ EDTA. All culture media and supplements were purchased from Thermo Fisher Scientific, Inc. 293T cells were cultured in DMEM:F12 with phenol red containing $10 \%$ heat-inactivated FBS. Cells were tested for the absence of Mycoplasma every other week using MycoAlert ${ }^{\circledR}$ mycoplasma detection kit (cat. nos. LT07-318 and
LT07-518; Lonza Group AG). All cell lines were authenticated by Eurofins Human Cell Line Authentication Services.

The COV434-AMHRII and SKOV3-AMHRII cell lines were generated by transfection of the cDNA encoding full-length human AMHRII as previously described (17). The cDNA encoding full-length human AMHRII in the pCMV6 plasmid (gifted by Dr Teixeira, Pediatric Surgical Research Laboratories, Massachusetts General Hospital, Harvard Medical School, Boston, USA) was first subcloned in the pcDNA3.1.myc-His vector (Invitrogen; Thermo Fisher Scientific, Inc.) using the EcoRI and XhoI restriction sites (enzymes from New England BioLabs, Inc.), and subsequently, using the EcoRI and SalI sites, in the pIRES1-EGFP vector, gifted by Dr F Poulat (Institut de Génétique Humaine, CNRS, Montpellier, France). At $24 \mathrm{~h}$ prior to transfection, COV434 cells were seeded in 150-mm cell culture dishes at $80 \%$ confluence. The AMHRII construct was transfected using the Fugene transfection kit (Promega Corporation) according to the manufacturer's protocol. Following a 48-h incubation at $37^{\circ} \mathrm{C}$, the transfection medium was replaced with fresh medium containing $0.5 \mathrm{mg} / \mathrm{ml}$ geneticin and was subsequently changed twice per week for two weeks. The cells were harvested and sorted using a FACSAria cytometer (Becton-Dickinson and Company) in 96-well plates. For each cell line, a clone that strongly expressed AMHRII was selected and designated as COV434-AMHRII and SKOV3-AMHRII, respectively (Fig. S3).

Primary tumor cells from ascites. Ascites samples from three patients with ovarian cancer were obtained from the Institut du Cancer de Montpellier (ICM) according to the French laws and after their informed written consent. All patient samples and data were retrieved from the ICM ovarian cancer clinical-biological database that had been approved by the independent Sud Méditerranée III Ethics Committee (study reference, 2016.09.06). Patients were chemotherapy-naïve and waiting for surgical intervention. Freshly obtained ascites were aliquoted in $50 \mathrm{ml}$ conical centrifuge tubes and centrifuged at $300 \mathrm{x} \mathrm{g}$ for $5 \mathrm{~min}$ at $4^{\circ} \mathrm{C}$. Cell pellets were resuspended in ammonium-chloride-potassium buffer ( $\mathrm{pH}: 7.2)(150 \mathrm{nM}$ $\mathrm{NH}_{4} \mathrm{Cl}, 10 \mathrm{nM} \mathrm{KHCO} 3$ and $0.1 \mathrm{nM} \mathrm{Na}_{2}$ EDTA) to lyse red blood cells on ice for $5 \mathrm{~min}$. The process was repeated until the lysis was complete. Subsequently, the cell pellets were plated in 150-mm cell culture dishes with $20 \mathrm{ml}$ DMEM F12-Glutamax (Gibco; Thermo Fisher Scientific, Inc.) and 10\% FBS. Cells were subsequently plated in DMEM:F12 with 10\% FBS for $30 \mathrm{~min}$ to rapidly eliminate adherent fibroblasts as previously described (39). Non-adherent cells were transferred to new dishes with DMEM:F12 and 10\% FBS. Low-passage (between 2 and 6) cells were used for experiments or frozen in liquid nitrogen.

Small interfering (si)RNA transfection. siRNA sequences were designed using the Rosetta algorithm by Sigma-Aldrich; Merck KGaA. A pool of three siRNAs (siRNA Nano Scale; Sigma-Aldrich; Merck KGaA) was used for each ALK receptor (ALK2: SIHK0175, SIHK0173, SIHK0174; ALK3: SIHK0170, SIHK0171, SIHK0172; ALK6: SIHK0175, SIHK0173, SIHK0174). MISSION esiRNA (cat. no. EHU121781; Sigma-Aldrich; Merck KGaA), a heterogeneous mixture of 
siRNA that target human AMH, was used to silence AMH. COV434-AMHRII and SKOV3-AMHRII cells were plated in 24-well plates at $60-80 \%$ confluency. Transfection was performed in DMEM:F12 medium with 1\% FBS using Lipofectamine ${ }^{\circledR}$ RNAiMax Transfection Reagent diluted in Opti-MEM Medium (cat. nos. 13778-150 and 11058021; Invitrogen; Thermo Fisher Scientific, Inc.) according to the manufacturer' s instructions. siRNAs were diluted to $3 \mathrm{pM}$, and the siRNA-Lipofectamine (1:1) mixture was added to the cells for $6 \mathrm{~h}$ at $37^{\circ} \mathrm{C}$. Cells were washed and cultured in DMEM: F12 with 1\% FBS. Experiments with siRNA-transfected cells were performed at 24 (COV434-AMHRII cells) or 48 (SKOV3-AMHRII cells) h post-transfection.

Western blot analysis. Cells were washed with PBS and scraped immediately in RIPA lysis buffer (Santa Cruz Biotechnology, Inc.) with 200 mM PMSF, 100 mM sodium orthovanadate and a protease inhibitor cocktail. The protein concentration was determined using the BCA assay protein quantitation kit (Interchim). Cell extracts were heated at $95^{\circ} \mathrm{C}$ for $5 \mathrm{~min}$, separated (50 $\mu \mathrm{g}$ protein/lane) by $10 \% \mathrm{SDS}-\mathrm{PAGE}$ in reducing conditions ( $5 \%$ 2 3 -mercaptoethanol), and transferred to PVDF membranes (Bio-Rad Laboratories, Inc.). The membranes were blocked in Tris-buffered saline with $0.1 \%$ Tween-20 and 5\% non-fat dry milk, and probed with the relevant primary antibodies at RT for $1 \mathrm{~h}$. Following washing with PBS-Tween $0.01 \%$, peroxidase-conjugated IgG secondary antibodies were added $(1: 10,000)$ at RT for $1 \mathrm{~h}$. After washing, antibody-antigen interactions were detected using Immobilon ${ }^{\circledR}$ ECL Ultra Western HRP Substrate (Merck KGaA). To verify equal loading, immunoblots were also probed with an anti-GAPDH monoclonal antibody diluted at 1:1,000 (cat. no. 8884; Cell Signaling Technology, Inc.).

Reversetranscription-PCR.RNA from $1 \times 10^{6}$ COV434-AMHRII and SKOV3-AMHRII cells was extracted using the RNeasy Mini Kit (Qiagen $\mathrm{GmbH}$ ) according to the manufacturer' $\mathrm{s}$ instructions. A total of $1 \mu \mathrm{g}$ RNA was reverse transcribed using SuperScript III Reverse Transcriptase kit (Thermo Fisher Scientific, Inc.) according to the manufacturer's instructions. PCR was performed to amplify the cDNA sequences with specific primers for each ALK receptor using the Dream Taq Green PCR Master Mix (Thermo Fisher Scientific, Inc.), $10 \mu \mathrm{M}$ primers and $2.5 \mu \mathrm{l}$ cDNA with the following conditions: initial denaturation at $95^{\circ} \mathrm{C}$ for $10 \mathrm{~min}$, followed by 40 cycles of $95^{\circ} \mathrm{C}$ for $60 \mathrm{sec}, 56.9^{\circ} \mathrm{C}$ for $90 \mathrm{sec}$ and $72^{\circ} \mathrm{C}$ for $90 \mathrm{sec}$, and final extension at $72^{\circ} \mathrm{C}$ for $5 \mathrm{~min}$. PCR analysis of Alk receptor expression was performed using the following primers: ALK2 forward, 5'-TTAAAAGGCGCAACCAAGA-3' and reverse, 5'-CGTACAACGATCCCATTTCA-3'; ALK3 forward, 5'-TTTATGGCACCCAAGGAAAG-3' and reverse, 5'-TGGTATTCAAGGGCACATCA-3'; ALK6 forward, 5'-CTCAGGGAGCGACCTGGGCA-3' and reverse, 5'-GCGGCCCCAAATGCAGGGAT-3'. A total of $20 \mu \mathrm{l}$ of each PCR sample was used for agarose gel electrophoresis and visualized under UV using G:BOX (Pxi 4; Syngene).

AMH pathway analysis. OVCAR8, KGN, COV434-AMHRII and SKOV3-AMHRII cells were cultured in DMEM:F12 with $1 \%$ FBS medium overnight and incubated with LR-AMH
$(0-25 \mathrm{nM})$ at $37^{\circ} \mathrm{C}$ for $6 \mathrm{~h}$. Western blotting was performed as aforementioned using anti-phosphorylated (p)SMAD1/5 (cat. no. 9516Cell Signaling Technologies, Inc.), anti-pAKT (cat. no. 9271; Cell Signaling Technologies, Inc.), anti-cleaved caspase-3 (cat. no. 9661; Cell Signaling Technologies, Inc.), anti-cleaved PARP (cat. no. 9546; Cell Signaling Technologies, Inc.), anti-GAPDH, anti-ALK2 (cat. no. ab60158; Abcam) and anti-ALK3 (cat. no. ab38560; Abcam) primary antibodies diluted at 1:1,000 overnight at $4^{\circ} \mathrm{C}$, followed by anti-rabbit and anti-goat IgG HRP secondary antibodies (1:10,000; cat. nos. AP106P and AP188P; Sigma-Aldrich; Merck KGaA) at RT for $1 \mathrm{~h}$. Since previous studies demonstrated that total SMAD1/5, total AKT, uncleaved caspase-3 and uncleaved PARP were not modified under AMH treatment, these total proteins were not systematically blotted $(7,40,41)$.

Clonogenic survival.COV434-AMHRII and SKOV3-AMHRII cells were plated in 24-well plates (50 cells/well) in DMEM:F12 with $1 \% \mathrm{FBS}$ and cultured overnight under normal culture conditions $\left(5 \% \mathrm{CO}_{2}, 37^{\circ} \mathrm{C}\right)$. LR-AMH $(0-25 \mathrm{nM})$ was subsequently added to the medium for 11 days. For COV434-AMHRII cells, the colonies were fixed in methanol/acetic acid solution (3:1) at $4^{\circ} \mathrm{C}$ for $20 \mathrm{~min}$, stained with $10 \%$ Giemsa and visible clones were counted manually. For SKOV3-AMHRII cells, for which direct clone counting was difficult, the Giemsa-stained clones were bleached with $70 \%$ ethanol for $30 \mathrm{~min}$ at RT, and the bleaching solution was analyzed at $595 \mathrm{~nm}$ by a plate reader to obtain a global estimate of the clone number and size.

Apoptosis assay. Apoptosis initiation was determined using the Caspase-Glos-3/7 assay (cat. no. G8090; Promega Corporation). Cells plated in white 96 -well plates were incubated with LR-AMH $(0-25 \mathrm{nM})$ for $6 \mathrm{~h}$ at $37^{\circ} \mathrm{C}$. Upon addition of the proluminescent caspase-3/7 DEVD-aminoluciferin substrate, caspase-3/7 cleavage of this substrate releases aminoluciferin that is consumed by luciferase to produce a luminescent signal, proportional to the caspase-3/7 activity. The luminescent signal was quantified with a PHERASTAR microplate reader $30 \mathrm{~min}$ after substrate addition.

Apoptosis was assessed using the Annexin V-FITC Apoptosis Detection kit (cat. no. IM3614; Beckman Coulter, Inc.). A total of $\sim 1 \times 10^{5}$ COV434-AMHRII and SKOV3-AMHRII cells/well were seeded in 24-well plates and incubated with or without $25 \mathrm{nM}$ LR-AMH, or $150 \mathrm{nM}$ staurosporin (positive control) for $24 \mathrm{~h}$. Adherent and detached cells were collected and centrifuged at $200 \mathrm{x}$ g for $5 \mathrm{~min}$ at $4^{\circ} \mathrm{C}$. Following washing with PBS, cells were stained with $130 \mu 1$ of a mixture containing $10 \mu \mathrm{l}$ FITC-labeled Annexin V and $20 \mu \mathrm{l}$ 7AAD in $10 \mu \mathrm{l}$ annexin buffer on ice in the dark for $15 \mathrm{~min}$. Following addition of $400 \mu \mathrm{l}$ annexin buffer, the fluorescence data were acquired by a Kaluza flow cytometer (Beckman Coulter, Inc.) within $30 \mathrm{~min}$, and analyzed with the Kaluza Flow Analysis software 2.1 (Beckman Coulter, Inc.). Flow cytometry data were expressed as the percentage of FITC-, AAD- or FITC and AAD-positive cells in 5x10= counted cells.

Immunofluorescence. For each experiment, 3x10 4 OVCAR8, KGN, COV434-AMHRII and SKOV3-AMHRII cells were cultured on 22-mm square glass coverslips in $35-\mathrm{mm}$ culture dishes in DMEM:F12 with $10 \%$ FBS overnight at $37^{\circ} \mathrm{C}$. Cells 
were subsequently starved with $1 \%$ FBS medium for $24 \mathrm{~h}$ prior to incubation with $25 \mathrm{nM}$ LRMIS for $90 \mathrm{~min}$ at $37^{\circ} \mathrm{C}$. Cells were then fixed and permeabilized in $3.7 \%$ paraformaldehyde/PBS for $40 \mathrm{~min}$, washed twice with PBS and once with PBS/0.1\% BSA, and blocked with PBS/1\%BSA for $1 \mathrm{~h}$ at RT. Subsequently, cells were incubated with P3X63 (42) or 13R4 (30) (1:200; irrelevant antibodies used as negative controls), the anti-AMHRII 12G4, and anti-ALK2 (cat. no. AF637), anti-ALK3 (cat. no. AF346) and anti-ALK6 (cat. no. MAB5051) (all from R\&D Systems, Inc.) primary antibodies in the dark for $1 \mathrm{~h}$. Following three washes with PBS, cells were incubated with anti-goat (1:1,000; cat. no Ab6881; Abcam) or anti-mouse (1:1,000; cat. no Ab6785; Abcam) FITC-labeled secondary antibodies in PBS/0.1\% BSA for $1 \mathrm{~h}$, followed by three washes with PBS/0.1\% Tween-20 and three washes with PBS. Coverslips were mounted with EverBrite $^{\mathrm{TM}}$ Hardest Mounting Medium with DAPI (Biotium, Inc.,). For each cell line, $>150$ cells were examined to select the representative fields, and $\geq 3$ representative fields for each sample were analyzed the following day under a fluorescence Zeiss Axioplan 2 Imaging microscope (Zeiss AG). Receptor (green) and nucleus (blue) labeling were estimated with ImageJ bundled with 64-bit Java 1.8.0_172 (National Institutes of Health) using the Color Histogram plugin (http://rsb.info. nih.gov/ij/plugins/color-histogram.html) to present the data as receptor/nucleus ratios.

In vivo ovarian cancer cell xenograft assay. All animal experiments were performed in compliance with the guidelines of the French government and the INSERM regulations (agreement no. D34-172-27). Athymic nude Hsd female mice (6-8-week-old; Envigo RMS SARL) were used. At day 0 (D0), $7 \times 10^{6}$ human COV434-AMHRII cells in $150 \mu \mathrm{l}$ BD Matrigel ${ }^{\circledR}$ (ratio 1:1), were subcutaneously grafted into the right flank. Mice were anesthetized with inhaled isoflurane. Inhalation anesthesia was delivered by an induction chamber and a face mask with the following dosing: 4-5\% for induction; $1-2 \%$ for maintenance. At D14, when tumor volume reached $80-100 \mathrm{~mm}^{3}$, mice were randomized $(\mathrm{n}=8-10$ mice/group) and treatments $(17 \mathrm{mg} / \mathrm{kg}$ BsAbs or saline) were administered by intraperitoneal injection twice per week for 4 weeks. Tumor diameters (D) were measured in the 3 dimensions with a caliper once per week, and tumor volumes were calculated using the formula: Volume $=$ D $1 \times$ D2 $\times$ D3/2. Tumor growth inhibition was calculated as $\mathrm{T} / \mathrm{C} \%=$ (median tumor volume of treated group at day $\mathrm{X} /$ median tumor volume of control group at day X) x100. When the tumors reached a volume of $1,500 \mathrm{~mm}^{3}$, mice were sacrificed by exposure to $\mathrm{CO}_{2}$ without removing animals from their home cage with a flow rate displacing $20 \%$ of the cage volume per minute. The presumed death after exposure to carbon dioxide was confirmed based on careful assessment of the animal for unambiguous signs of death, such as cardiac arrest or fixed, dilated pupils. Sacrifice dates ranged from D31 (February 27th, 2020; first mouse in the saline control group) to D62 (March 29th, 2020; last mouse in the 12G4-2F9 BsAb group).

Statistical analysis. Statistical analyses of caspase-3/7 activity and cell viability/proliferation data were performed using GraphPad Prism software 7 (GraphPad Software, Inc.) by one-way ANOVA with Tukey' s multiple comparison test. Other statistical analyses were performed using the STATA 16.0 software (StataCorp LP). A linear mixed regression model was used to determine the association between tumor growth and the number of days post-graft. The fixed part of the model included variables corresponding to the number of days post-graft and the different groups. Interaction terms were built into the model. Random intercept and random slope were included to account for the time effect. The coefficients of the model were estimated by maximum likelihood. $\mathrm{P}<0.05$ was considered to indicate a statistically significant difference.

\section{Results}

Recombinant AMH induces AMH signaling in COV434-AMHRII and SKOV3-AMHRII cells. To enable the study of various AMHRIs in AMH/AMHRII signaling, two ovarian cancer cell lines that stably expressed AMHRII were established: COV434-AMHRII (17) and SKOV3-AMHRII. AMHRII expression levels in cell lines derived from ovarian carcinomas and ascites rapidly and progressively decrease after long-term culture $(9,15)$, thus limiting experimental reproducibility. The present study further aimed to determine whether $\mathrm{AMH}$ signaling and its downstream effects were intact in COV434-AMHRII and SKOV3-AMHRII cells. In both cell lines, SMAD1/5 phosphorylation was induced by increasing concentrations of the recombinant $\mathrm{AMH}$ protein LR-AMH $(9,26)$ (from 1.6 to $25 \mathrm{nM}$; Fig. 1A). Apoptosis, evaluated by measuring caspase-3/7 activity, was significantly induced compared with vehicle-treated cells starting at $12.5 \mathrm{nM}$ LR-AMH in COV434-AMHRII cells and at $6.3 \mathrm{nM}$ LR-AMH in SKOV3-AMHRII cells (Fig. 1B, upper panels). Apoptosis induction was further confirmed by western blot analysis of cleaved caspase-3/7 and cleaved PARP (Fig. 1B, lower panels). In addition, flow cytometry analysis results demonstrated that incubation with $25 \mathrm{nM}$ LR-AMH for $24 \mathrm{~h}$ increased the apoptotic rate in COV434-AMHRII cells compared with that in untreated cells (15.3 vs. 5.1\% Annexin V-positive cells and 11.8 vs. 5.6\% Annexin V/7AAD-positive cells), as well as in SKOV3-AMHRII cells compared with that in the corresponding untreated cells (8.5 vs. 7.4\% Annexin V-positive cells and 13.7 vs. $4.8 \%$ Annexin V/7AAD-positive cells) (Figs. 1C and S4). AMH concentrations of 6.2 and $25 \mathrm{nM}$ reduced the clonogenic ability by $>50 \%$ in COV434-AMHRII and SKOV3-AMHRII cells, respectively, compared with that in the corresponding untreated cells (Fig. 2). These results suggested that COV434-AMHRII and SKOV3-AMHRII cells may be suitable models to study the roles of ALK2, ALK3 and ALK6 in AMH signaling.

ALK3 mediates AMH-induced increase in the levels of phosphorylated SMADI/5 and caspase-3 and PARP activation in ovarian cancer cells. To analyze the involvement of AMHRI in AMH signaling in ovarian cancer cells, knockdown experiments were performed in COV434-AMHRII and SKOV3-AMHRII cells by transfecting a mixture of three siRNAs against each AMHRI. PCR and western blot analyses revealed that the siRNA mixtures against $A L K 2$ (siAlk2) and against $A L K 6$ (siAlk6) efficiently inhibited their expression (Fig. S5). By contrast, $A L K 3$ silencing (siAlk3) had limited 
A

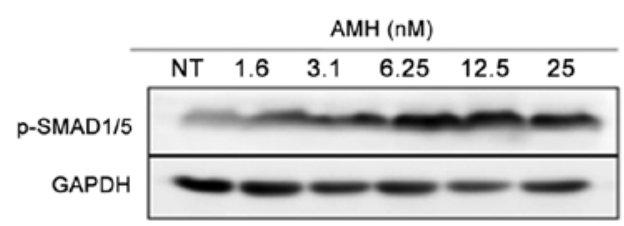

B

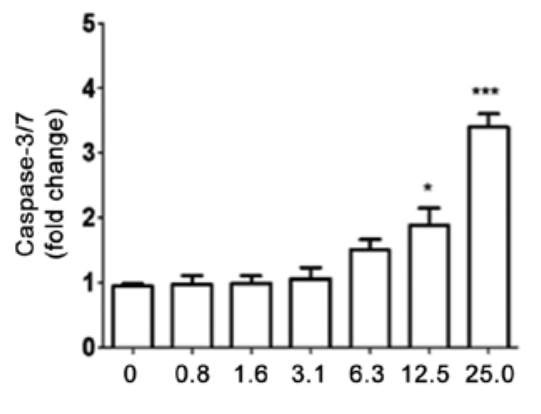

$\mathrm{AMH}$

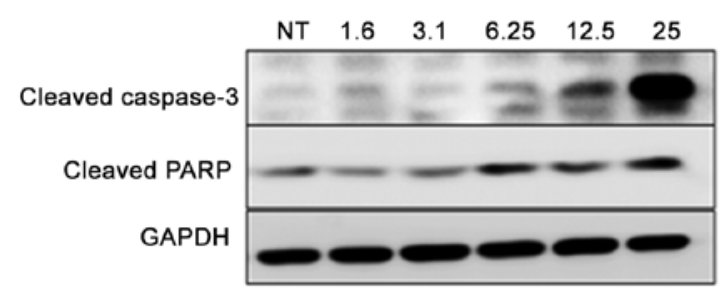

C

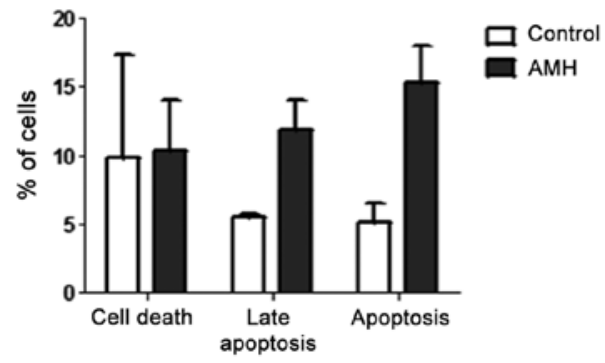

\section{SKOV3-AMHRII}
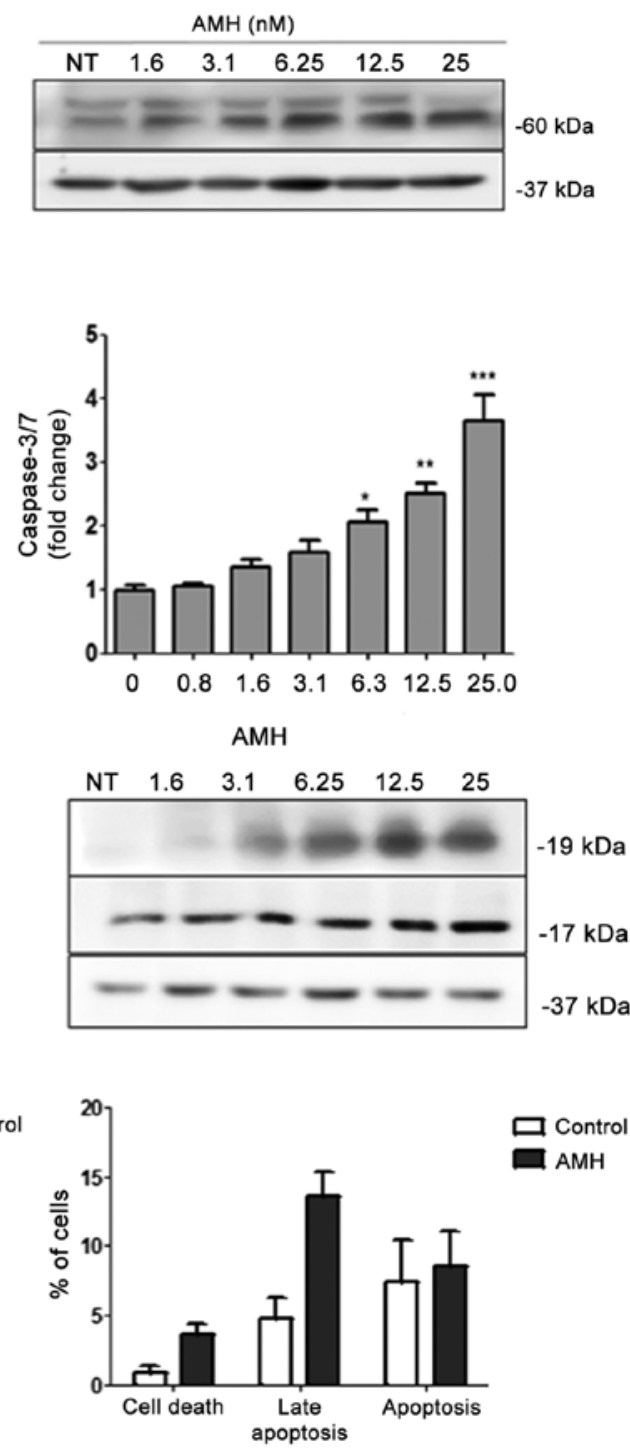

Figure 1. LR-AMH induces AMH signaling in COV434-AMHRII and SKOV3-AMHRII cells. (A and B) Incubation with 1.6-25 nM LR-AMH for 6 h increased the levels of (A) pSMAD1/5 and (B) apoptosis (upper panels, caspase-3/7 activity; middle panels, cleaved caspase-3 and PARP analysis by western blotting) compared with NT samples. (C) Apoptosis was also analyzed using the Annexin V-7AAD assay following incubation with $25 \mathrm{nM}$ LR-AMH for $24 \mathrm{~h}$. Data are presented as the mean \pm SEM. COV434-AMHRII, $n=3$; SKOV3-AMHRII, $n=4 .{ }^{*} \mathrm{P}<0.05,{ }^{* *} \mathrm{P}<0.01$ and ${ }^{* * * *} \mathrm{P}<0.001$ vs. control. Apoptosis, Annexin V-positive cells; late apoptosis, Annexin V/7AAD-positive cells; AMH, anti-Müllerian hormone; LR-AMH, active recombinant AMH; AMHRII, AMH type II receptor; PARP, poly(ADP-ribose) polymerase; NT, non-treated.

efficiency, particularly in COV434-AMHRII cells (Fig. S5). The effects of LR-AMH (at the supraphysiological concentration of $25 \mathrm{nM}$ for $6 \mathrm{~h}$ ) on the levels of pSMAD1/5 was subsequently evaluated in cells transfected with the siRNAs. The results demonstrated that only siAlk3 transfection suppressed the levels of pSMAD1/5 in COV434-AMHRII and SKOV3-AMHRII cells compared with those observed following siMock transfection (Fig. 3A). Similarly, levels of caspase-3/7 activity and cleavage in COV434-AMHRII and SKOV3-AMHRII cells were not significantly different in siAlk2- and siAlk6-transfected cells compared with those in the mock siRNA control cells (Fig. 3B, top). By contrast, initiation of apoptosis as measured by caspase- 3 cleavage was reduced by $\sim 25 \%$ in siAlk3-transfected COV434-AMHRII and SKOV3-AMHRII cells compared with those in the corresponding control cells (Fig. 3B, top). These results were validated by western blot analysis of cleaved PARP and caspase-3/7 levels (Fig. 3B, bottom). Taken together, these findings suggested that $\mathrm{AMH}$ signaling was significantly reduced only by Alk3 silencing (which was incomplete) in COV434-AMHRII and SKOV3-AMHRII cells, demonstrating that ALK3 may be the functional AMHRI receptor implicated in apoptosis of ovarian cancer cells exposed to supraphysiological AMH concentrations.

AMH concentration regulates the differential modulation of ALK2 and ALK3 expression, pSMAD1/5, cleaved caspase-3 and PARP, and pAKT levels. The present study subsequently investigated the consequences of exposure to $\mathrm{AMH}$ on AMHRII, ALK2, ALK3 and ALK6 expression levels in four AMHRII-positive ovarian cancer cell lines: COV434-AMHRII (sex cord stromal tumor) (36,37), SKOV3-AMHRII (high 

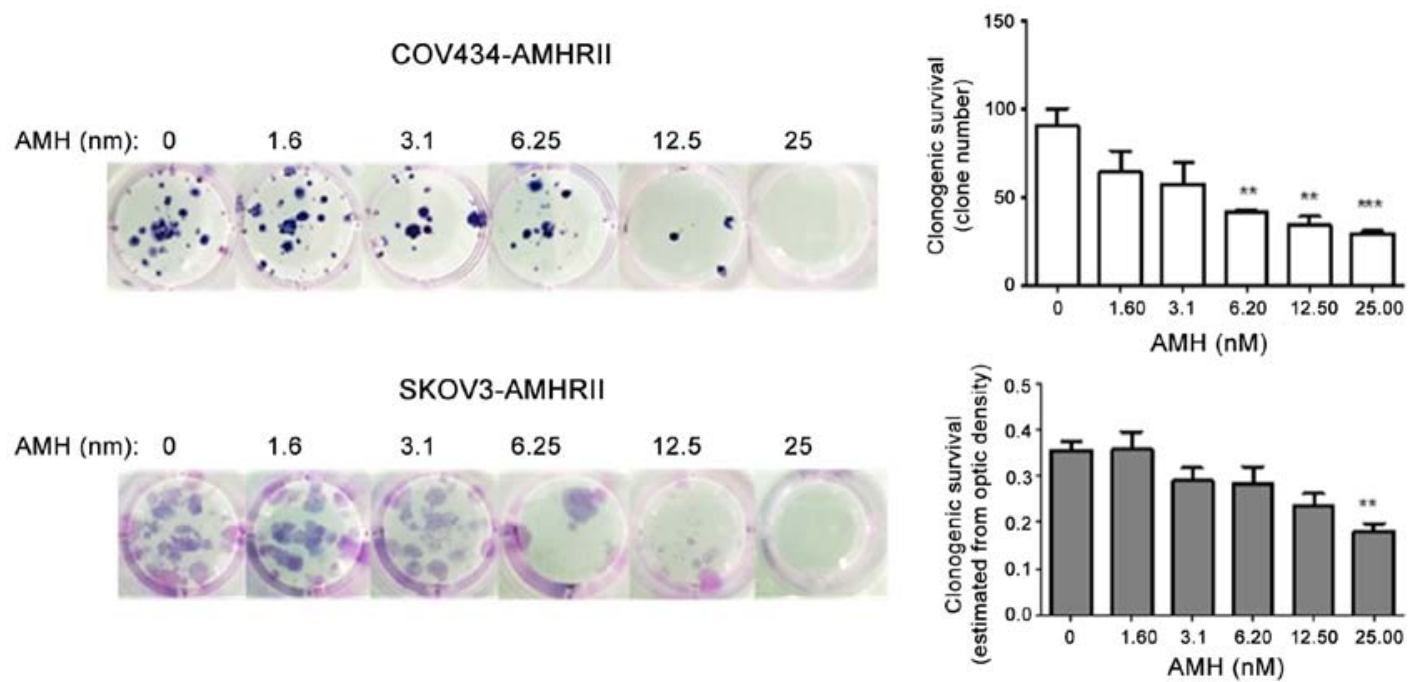

Figure 2. LR-AMH reduces the clonogenic ability of COV434-AMHRII and SKOV3-AMHRII cells. Clonogenic ability was determined following culture in the presence of 1.6-25 nM LR-AMH for 11 days by direct clone counting in COV434-AMHRII cells and by estimating the number of clones after cell lysis in SKOV3-AMHRII cells. Data are presented as the means \pm SEM. $n=4 .{ }^{* *} \mathrm{P}<0.01$ and ${ }^{* * *} \mathrm{P}<0.001$ vs. 0 nM LR-AMH. AMH, anti-Müllerian hormone; LR-AMH, active recombinant AMH; AMHRII, AMH type II receptor.

A
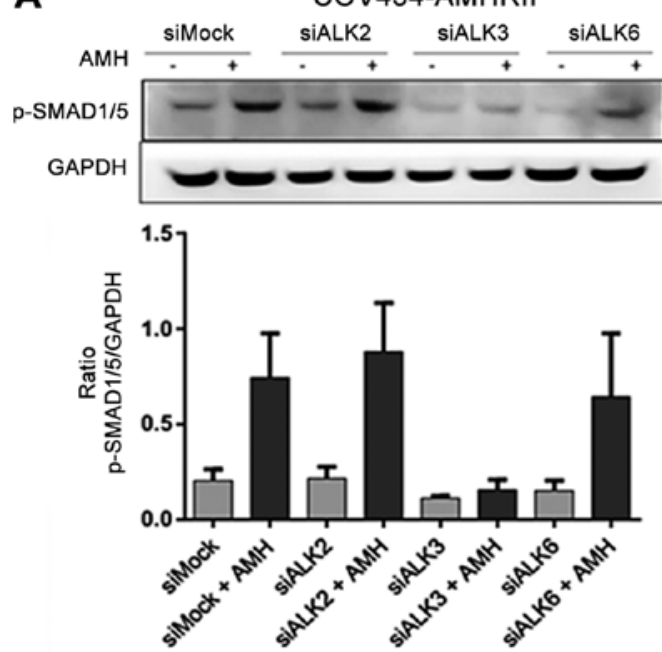

B

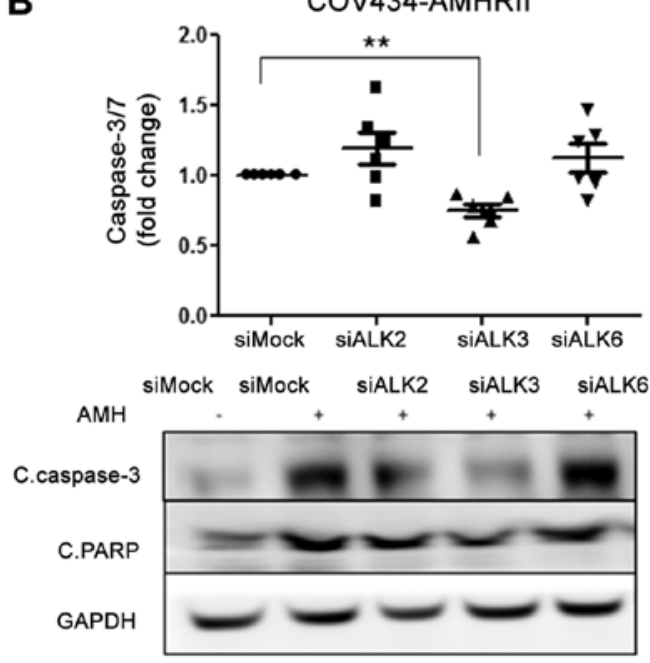

SKOV3-AMHRII
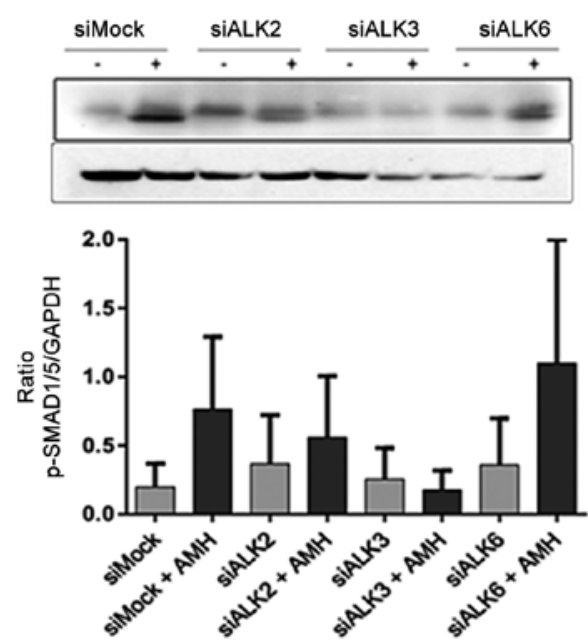

SKOV3-AMHRII
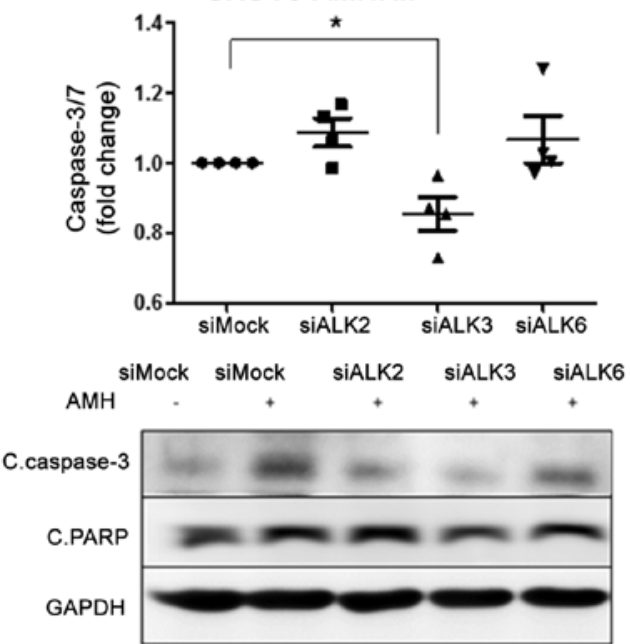

Figure 3. Involvement of ALK2, ALK3 and ALK6 in the effects of AMH in COV434-AMHRII and SKOV3-AMHRII cells. (A) pSMAD1/5 levels were evaluated following incubation with $25 \mathrm{nM}$ LR-AMH for $6 \mathrm{~h}$ starting 24 (COV434-AMHRII cells) or 48 (SKOV3-AMHRII cells) h post-transfection with si-ALK2, si-ALK3 and si-ALK6. Data are presented as the mean + max of pSMAD1/5:GAPDH ratios. n=2. (B) Caspase-3/7 activity and cleaved caspase-3 and PARP levels were analyzed following incubation with $25 \mathrm{nM}$ AMH for $6 \mathrm{~h}$ ( 24 and $48 \mathrm{~h}$ post-transfection). ${ }^{*} \mathrm{P}<0.05 ;{ }^{* *} \mathrm{P}<0.01$. AMH, anti-Müllerian hormone; LR-AMH, active recombinant AMH; AMHRII, AMH type II receptor; ALK, activin receptor-like kinase; si, small interfering RNA; p, phosphorylated; C., cleaved. 


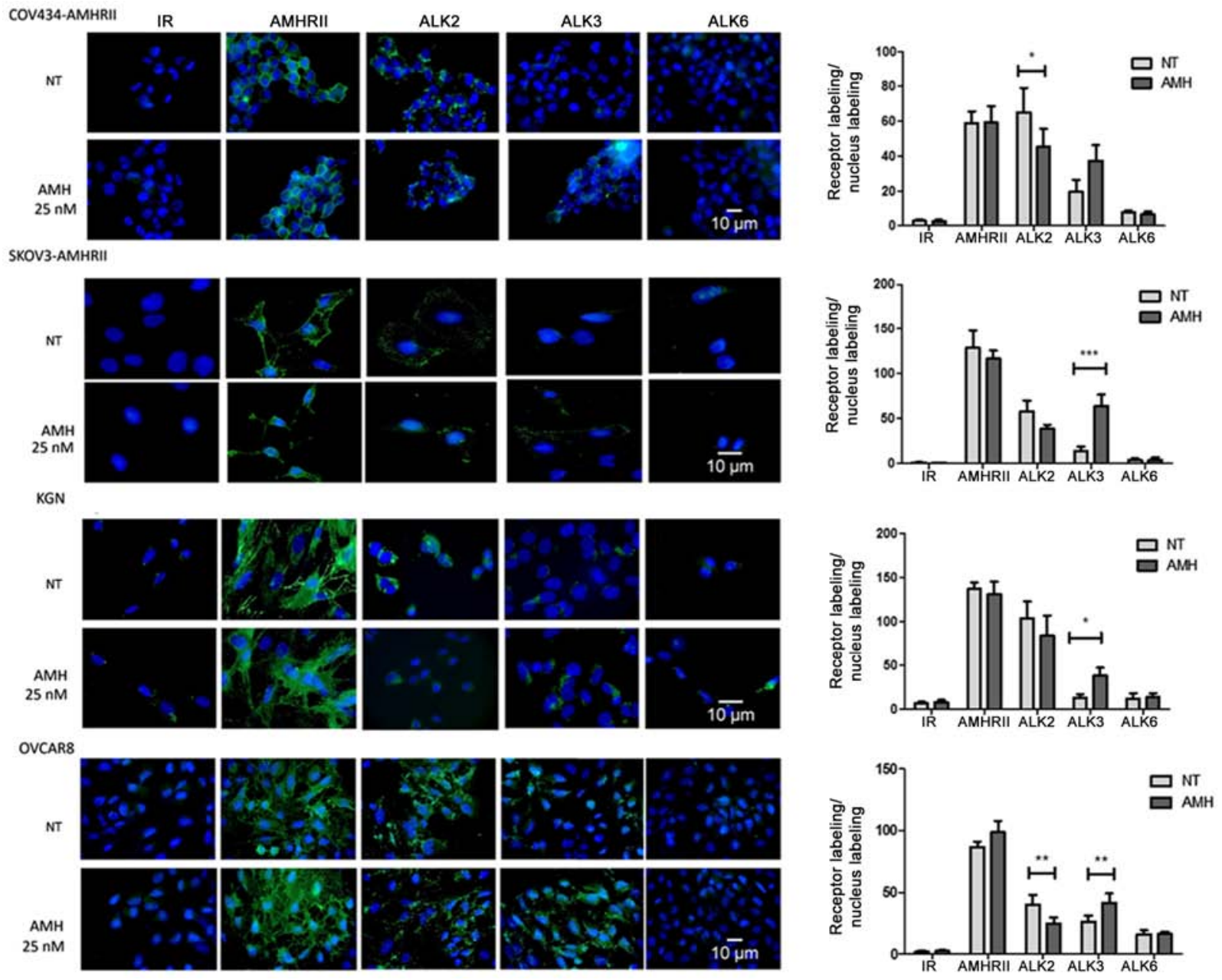

Figure 4. Incubation with recombinant LR-AMH modulates ALK2 and ALK3 expression in COV434-AMHRII, SKOV3-AMHRII, OVCAR8 and KGN ovarian cancer cells. Immunofluorescence analysis of AMHRII, ALK2, ALK3 and ALK6 expression in basal conditions and after incubation with $25 \mathrm{nM}$ LR-AMH for $90 \mathrm{~min}$. Data are presented as the ratio of receptor (green) and nucleus (blue) labeling. ${ }^{*} \mathrm{P}<0.05,{ }^{* * *} \mathrm{P}<0.01$ and ${ }^{* * * *} \mathrm{P}<0.001 \mathrm{n}=6$. AMH, anti-Müllerian hormone; LR-AMH, active recombinant AMH; AMHRII, AMH type II receptor; ALK, activin receptor-like kinase; IR, irrelevant antibody; NT, non-treated.

grade serous ovarian cancer), OVCAR8 (high grade serous ovarian cancer) and KGN (granulosa cell tumor) (38). These cell lines represent different ovarian cancer types and include AMHRII-transfected and non-transfected cell lines. AMHRII and ALK2 expression was detected in all four cell lines at physiological endogenous AMH concentration (basal conditions with $1 \%$ FBS corresponding to $10 \mathrm{pM}$ AMH). AMHRII expression was not modulated by incubation with supraphysiological LR-AMH concentrations ( $25 \mathrm{nM}$ for $90 \mathrm{~min}$ ), whereas ALK 2 expression was decreased by $\sim 30 \%$ compared with that under basal conditions, as estimated by immunofluorescence quantification of receptor/nucleus labeling (Fig. 4). In all four cell lines, ALK3 expression was not detected at physiological endogenous AMH concentrations, but only following exposure to $25 \mathrm{mM}$ LR-AMH (Fig. 4). ALK6 was not detectable at either AMH concentration, suggesting that this AMHRI may not be implicated in the present experimental conditions. Therefore, the present study further focused on ALK2 and ALK3.

To determine the roles of ALK2 and ALK3, their expression levels as well as the levels pSMAD1/5 were assessed in basal conditions and following incubation with increasing concentrations of LR-AMH (1.6-25 nM) for $6 \mathrm{~h}$. In all four cell lines, ALK2 expression decreased upon incubation with increasing concentrations of LR-AMH, and was almost undetectable between 6.25 and 12.5 nM LR-AMH (Figs. 5 and S6). By contrast, ALK3 expression levels increased following LR-AMH exposure compared with those in the untreated cells. In addition, the levels of pSMAD1/5 and cleaved caspase-3 and PARP increased concomitantly with ALK3 expression (Figs. 5 and S6). To analyze the involvement of non-canonical pathways in AMH signaling $(41,43)$, pAKT levels were also detected; the results demonstrated that the levels of pAKT decreased following incubation with LR-AMH, similar to the ALK2 expression levels (Figs. 5 and S6).

The same analyses were subsequently repeated in cancer cells isolated from ascites samples of three patients with ovarian cancer. and similar results were observed (Figs. 6 and S7) with a certain amount of variability. The sampled tumors were high-grade papillary serous carcinomas, of which two harbored wild-type BRCA1 and one presented with mutated BRCA1. The AMH concentration required to induce apoptosis, determined by the levels of cleaved caspase-3 and PARP, appeared to be higher compared with that used in cell lines (50 vs. $25 \mathrm{nM}$ ). Notably, despite the enhanced expression levels of apoptotic markers, pSMAD1/5 levels were paradoxically decreased in 

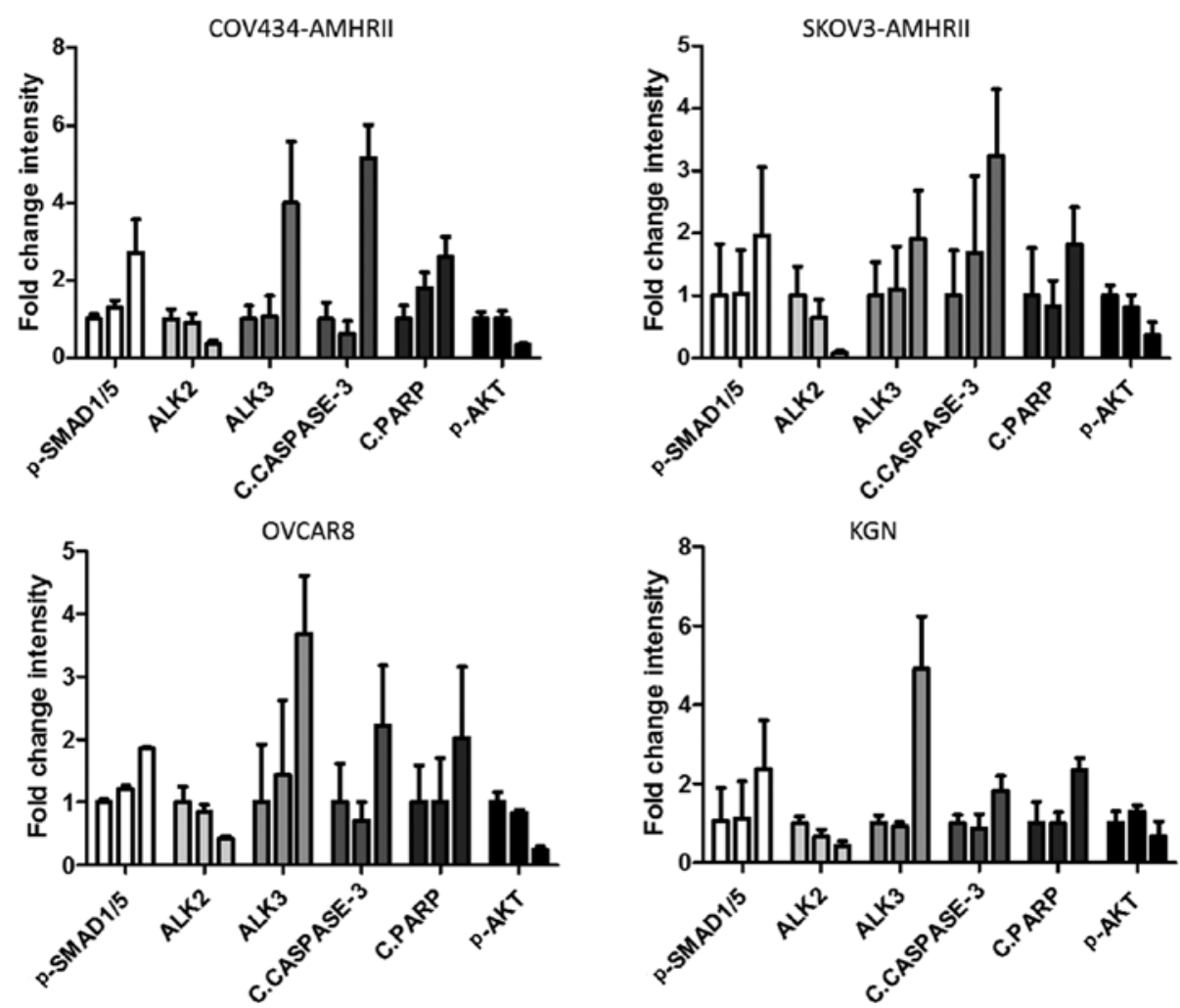

Figure 5. Differential expression of ALK2 and ALK3 following LR-AMH treatment is associated with the expression of cell survival and apoptosis markers in COV434-AMHRII, SKOV3-AMHRII, OVCAR8 and KGN ovarian cancer cells. Quantification of the western blot analysis of AMH signaling (pSMAD1/5), ALK2 and ALK3 expression, apoptosis induction (cleaved caspase-3 and PARP) and pAKT levels following incubation with 1.6 and $25 \mathrm{nM} \mathrm{LR}-\mathrm{AMH}$ for $6 \mathrm{~h}$. Data are presented as the fold-change relative to control (no LR-AMH) by bars corresponding from left to right to $0,1.6$ and $25 \mathrm{nM}$ for each protein expression. $\mathrm{n}>3$. Raw data are presented in Fig. S5. AMH, anti-Müllerian hormone; LR-AMH, active recombinant AMH; AMHRII, AMH type II receptor; ALK, activin receptor-like kinase; $p$, phosphorylated; c, cleaved; PARP, poly(ADP-ribose) polymerase.

cells incubated with $50 \mathrm{nM}$ recombinant AMH compared with those in cells treated with $25 \mathrm{nM}$ AMH.

These results suggested that in ovarian carcinoma cells, supraphysiological AMH concentrations induced ALK3 and inhibited ALK2 expression, and that this shift may be associated with proapoptotic signaling.

Anti-AMHRII-ALK2 and anti-AMHRII-ALK3 bispecific antibodies affect AMH/AMHRII signaling. As differential roles of ALK2 and ALK3 in AMH/AMHRII signaling were observed in ovarian cancer cells, the present study developed antibodies against these receptors to induce apoptosis in these cells. To limit side effects due to the ubiquitous expression of ALK2 and ALK3, bispecific antibodies (BsAbs) against AMHRII and ALK2, and against AMHRII and ALK3 were developed. The presence of the antibody fragment against AMHRII (the tumor-specific receptor) conferred tumor specificity to the BsAbs (Fig. S2). A total of eight anti-ALK2 and six anti-ALK3 $\mathrm{scFv}$ antibodies were isolated from the human $\mathrm{scFv}$ phage display library Husc I $(30,31)$. For each ALK receptor, the two most efficient binders in ELISA assays were formatted as full human IgG1 and BsAbs (Table I). For all antibodies and targets, the $\mathrm{EC}_{50}$ of the IgG1 and BsAbs were comparable. The mean $\mathrm{EC}_{50}$ of the MAb $12 \mathrm{G} 4$ was $0.34 \mathrm{nM}$, which was close to its known $\mathrm{KD}(0.8 \mathrm{nM})(11,15)$. To favor BsAb targeting by the anti-AMHRII arm, affinity maturation of the anti-ALK2 and anti-ALK3 $\mathrm{scF}$ v was not performed, providing an advantage to the $12 \mathrm{G} 4 \mathrm{arm}$.
Anti-AMHRII-ALK2 BsAb 12G4-2F9 reduces the growth of COV434-AMHRII cell xenografts in vivo. To evaluate the in vivo antitumor activity of the anti-AMHRII-AMHRI BsAbs, mice with established COV434-AMHRII cell xenografts (8-10 mice/group) were treated with the two anti-AMHRII-ALK2 BsAbs (12G4-2C1 and 12G4-2F9), the two anti-AMHRII-ALK3 BsAbs (12G4-3D7 and 12G4-3H6), vehicle control ( $\mathrm{NaCl})$ or a control BsAb against AMHRII and CD5 (12G4-CD5) $(32,35)$. The 12G4-CD5 BsAb was used as a control that retained AMHRII recognition, but bound to an irrelevant antigen (CD5) instead of ALK2 and ALK3. Mice received $17 \mathrm{mg} / \mathrm{kg}$ of BsAb (molar equivalent to $10 \mathrm{mg} / \mathrm{kg}$ for MAbs) by i.p. injection twice per week for 4 weeks. Treatment started at D14 after tumor grafting (mean tumor volume, $85 \mathrm{~mm}^{3}$; no differences among the six groups). On D31, when tumor volumes reached $1,500 \mathrm{~mm}^{3}$ in three mice of the saline vehicle group (mean \pm SEM, $1180 \pm 201 \mathrm{~mm}^{3}$ ), the mean tumor volume was lower in the antibody-treated groups, including that in mice treated with the control BsAb 12G4-CD5, suggesting baseline efficacy by the anti-AMHRII Fab alone $\left(709 \pm 110 \mathrm{~mm}^{3}\right)$. The tumor volumes in mice treated with the anti-AMHRII-ALK3 BsAbs 12G4-3D7 and 12G4-3H6, or the anti-AMHRII-ALK2 BsAb 12G4-2C1 $\left(671 \pm 92.3,669 \pm 111.8\right.$ and $620 \pm 102 \mathrm{~mm}^{3}$, respectively) were not significantly different compared those in mice treated with the control anti-AMHRII BsAb 12G4-CD5 (Fig. 7). By contrast, mice treated with the AMHRII-ALK2 12G4-2F9 BsAb developed significantly smaller tumors $\left(484 \pm 95 \mathrm{~mm}^{3}\right)$ compared with those treated with the control BsAb 12G4-CD5. Accordingly, the 
Patient 1

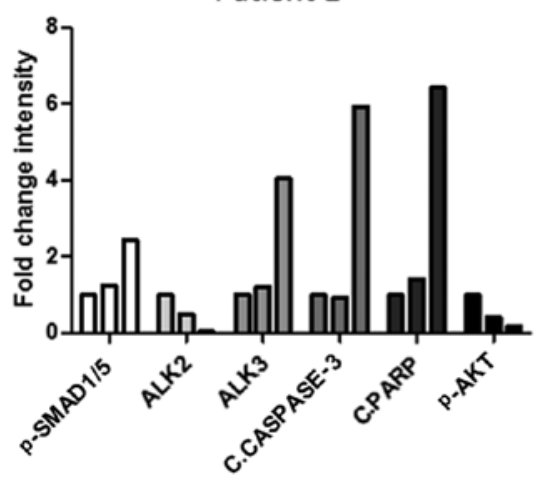

Patient 3

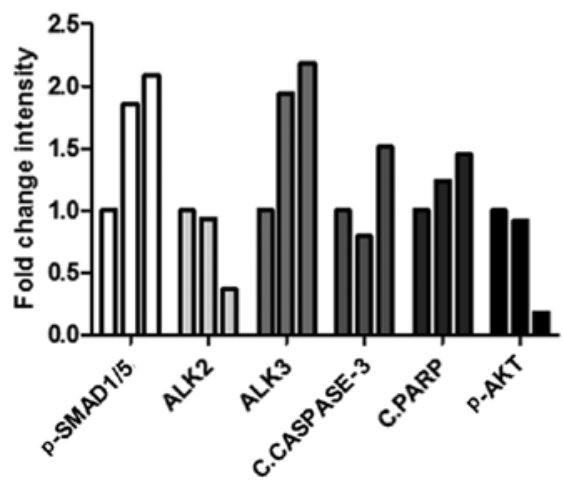

Patient 2

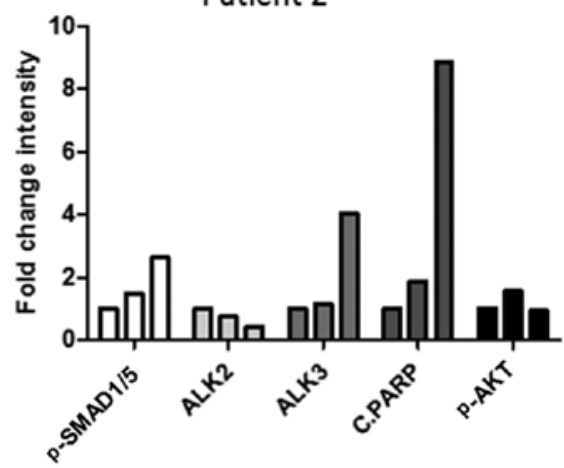

Figure 6. Differential expression of ALK2 and ALK3 following LR-AMH treatment is associated with the expression of cell survival and apoptosis markers in primary ovarian cancer cells. Quantification of the western blot analysis of AMH signaling (pSMAD1/5), ALK2 and ALK3 expression, apoptosis induction (cleaved caspase-3 and PARP) and pAKT levels following incubation of cells isolated from ascites of three patients with ovarian cancer with 1.6 and $25 \mathrm{nM}$ LR-AMH for $6 \mathrm{~h}$. Data are presented as the fold change relative to control (no LR-AMH) by bars corresponding from left to right to $0,1.6$ and $25 \mathrm{nM}$ for each protein expression. $\mathrm{n}=1$ for each patient. Raw data are presented in Fig. S6. AMH, anti-Müllerian hormone; LR-AMH, active recombinant AMH; AMHRII, AMH type II receptor; ALK, activin receptor-like kinase; P, phosphorylated; c, cleaved; PARP, poly(ADP-ribose) polymerase.
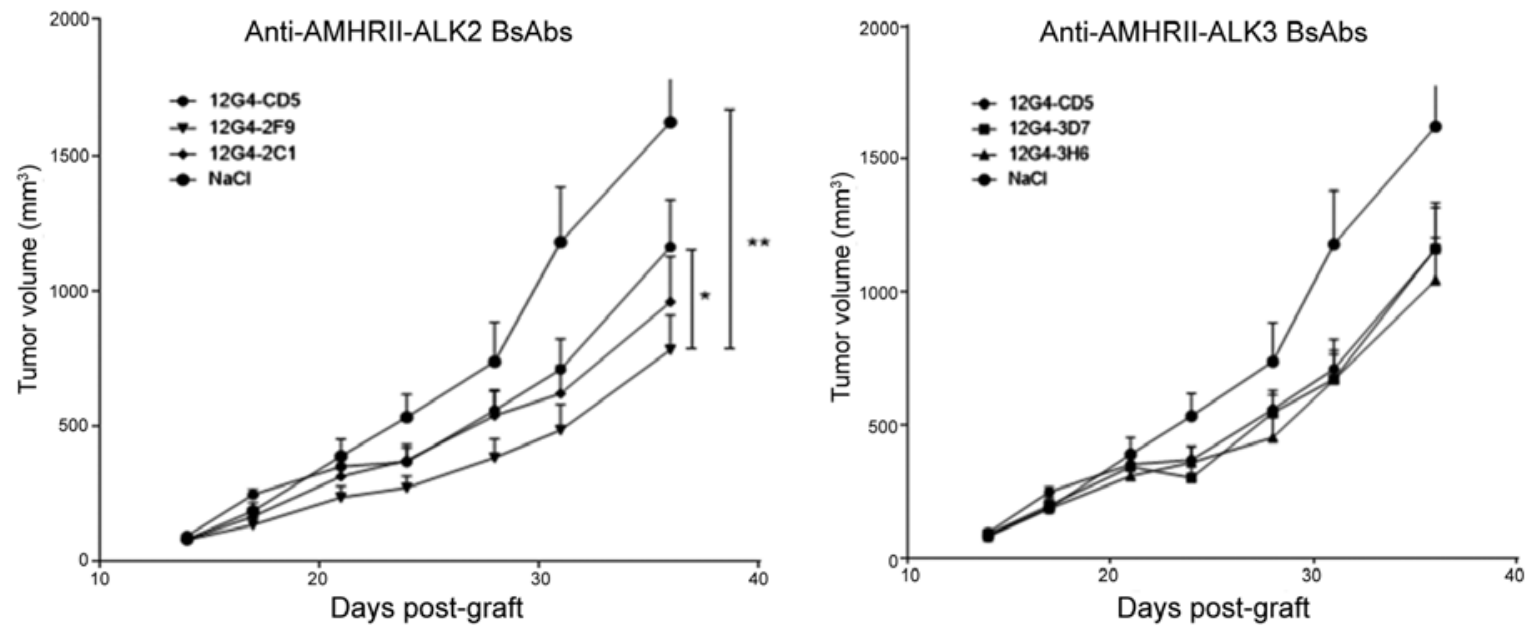

Figure 7. The anti-AMHRII-ALK2 BsAb 12G4-2F9 inhibits the growth of COV434-AMHRII cell xenografts in vivo. Nude mice bearing COV434-MISRII cell-derived tumors were treated with $17 \mathrm{mg} / \mathrm{kg}$ of anti-AMHRII-CD5 (control BsAb targeting AMHRII and CD5), anti-AMHRII-ALK2 (12G4-2C1 and 12G4-2F9), anti-AMHRII-ALK3 (12G4-3D7 and 12G4-3H6) BsAbs or vehicle ( NaCl) twice per week for 4 weeks. Data are presented as the mean \pm SEM. ${ }^{*} \mathrm{P}<0.05$ and $^{* *} \mathrm{P}<0.01$. AMHRII, anti-Müllerian hormone type II receptor; ALK, activin receptor-like kinase; BsAbs, bispecific antibodies.

$\mathrm{T} / \mathrm{C} \%$ values of the $12 \mathrm{G} 4-2 \mathrm{C} 1$ and $12 \mathrm{G} 4-2 \mathrm{~F} 9 \mathrm{Bs}$ Abs were 52 and $41 \%$, respectively. Throughout the experiment, tumor growth was significantly lower in the antibody-treated mice compared with that in the vehicle group (vehicle vs. 12G4-3D7, $\mathrm{P}=0.018$; vehicle vs. $12 \mathrm{G} 4-\mathrm{CD} 5,12 \mathrm{G} 4-2 \mathrm{C} 1$ or $12 \mathrm{G} 4-3 \mathrm{H} 6, \mathrm{P}=0.001$ ) (Fig. 7). However, only tumor growth in 12G4-2F9-treated mice was statistically lower compared with that in the 12G4-CD5 group $(\mathrm{P}=0.048)$. 
Table I. Affinity of the MAbs and BsAbs for their targets estimated by assessing the $\mathrm{EC}_{50}$ by ELISA.

\begin{tabular}{|c|c|c|c|}
\hline \multirow[b]{2}{*}{ Antibody } & \multicolumn{3}{|c|}{$\mathrm{EC}_{50}, \mathrm{nM}$} \\
\hline & AMHRII & ALK2 & ALK3 \\
\hline $12 \mathrm{G} 4$ & $0.35 \pm 1.42$ & & \\
\hline $2 \mathrm{C} 1$ & & $26.80 \pm 1.30$ & \\
\hline $2 \mathrm{~F} 9$ & & $74.56 \pm 1.41$ & \\
\hline $3 \mathrm{D} 7$ & & & $50.03 \pm 1.90$ \\
\hline $3 \mathrm{H} 6$ & & & $2.07 \pm 2.13$ \\
\hline
\end{tabular}

B, BsAbs

\begin{tabular}{lccr}
\hline & \multicolumn{3}{c}{$\mathrm{EC}_{50}, \mathrm{nM}$} \\
\cline { 2 - 4 } Antibody & AMHRII & ALK2 & \multicolumn{1}{c}{ ALK3 } \\
\hline $12 \mathrm{G} 4-2 \mathrm{C} 1$ & $0.28 \pm 1.56$ & $29.93 \pm 1.26$ & \\
$12 \mathrm{G} 4-2 \mathrm{~F} 9$ & $0.64 \pm 1.46$ & $85.56 \pm 1.36$ & \\
$12 \mathrm{G} 4-3 \mathrm{D} 7$ & $0.39 \pm 1.64$ & & $48.45 \pm 1.41$ \\
$12 \mathrm{G} 4-3 \mathrm{H} 6$ & $0.30 \pm 1.57$ & & $1.14 \pm 1.41$ \\
\hline
\end{tabular}

MAb, monoclonal antibody; BsAb, bispecific antibody; ALK, activin receptor-like kinase; $\mathrm{EC}_{50}$, half maximal effective concentration.

\section{Discussion}

The AMH/AMHRII signaling pathway has been studied during development, but the role of the three AMHRIs ALK2, ALK3 and ALK6 in the physiological effects of AMH has not been fully elucidated. Similar to other TGF $\beta$ family members, these effects are dependent on cellular context (44). The predominant AMHRI partner to AMHRII depends on the cell type, as demonstrated in Sertoli (18), Leydig (20) and granulosa cells (22), and on the development stage during Müllerian duct regression (19-21,24). During embryogenesis, the spatiotemporal patterns of ALK2 and ALK3 expression suggest that they act sequentially as AMHRIs by high-dose AMH-induced signaling (42.5 nM in in vitro experiments) (24). ALK2 is implicated at the early stages of Müllerian duct regression that involve the epithelial-mesenchymal transition, whereas ALK3 acts later during apoptosis (24). Orvis et al (21) have reported that following AMH binding to the AMHRII expressed on the duct mesenchyme, ALK2 and ALK3 act redundantly in a complex with AMHRII to activate the Müllerian duct mesenchyme signals responsible for the regression of the Müllerian duct mesoepithelium. These experiments have also suggested that AMH uses ALK3 as its primary AMHRI to induce regression through apoptosis (21). Thus, the balance between ALK2 and ALK3 recruitment may differently affect AMHRII-mediated cell fate during embryogenesis. In cancer, little is known about the contribution of the various AMHRIs to AMH-AMHRII signaling. Basal et al (25) analyzed the expression of AMHRII, ALK2, ALK3 and ALK6 by immunohistochemistry in 262 epithelial ovarian carcinoma samples; AMHRII was expressed in $73.4 \%$ of the samples, as previously reported $(5,11,45,46)$. In the 235 samples in which all four receptors could be assessed, 36\% expressed AMHRII/ALK2/ALK3/ALK6, 34\% AMHRII/ALK2/ALK3, $18 \%$ ALK2/ALK3, and 7\% ALK2/ALK3/ALK6, and these expression profiles were not associated with the disease stage, overall or disease-free survival (25). In the present study, using two ovarian cancer cell lines COV434-AMHRII and SKOV3-AMHRII, ALK3 was demonstrated to be the predominant AMHRI responsible for AMH signaling, resulting in the induction of apoptosis. In four ovarian cancer cell lines (COV434-AMHRII, SKOV3-AMHRII, OVCAR8 and KGN), ALK2 and ALK3 membrane expression was demonstrated to depend on LR-AMH concentration: ALK2 was expressed at physiological endogenous AMH concentration $(<10 \mathrm{pM})$, whereas ALK3 was preferentially expressed at supraphysiological concentrations and was responsible of apoptosis induction. These results were validated in tumor cells isolated from ascites samples of three patients with ovarian carcinoma.

Based on these differential roles of ALK2 and ALK3 in AMH/AMHRII signaling in ovarian cancer cells, the present study designed BsAbs against AMHRII and ALK2, and against AMHRII and ALK3 that reduced tumor growth in ovarian cancer. The BsAb strategy used in the present study allowed us to overcome potential side effects due to the ubiquitous expression of ALK2 and ALK3 (47), since the anti-AMHRII antibody fragments conferred tumor specificity.

BsAbs are one of the pillars of the next-generation antibody drugs $(48,49)$. A limited number of BsAbs are currently used in the clinic, for instance catumaxomab (CD3-EpCam) and blinatumomab (CD3-CD19); however, $>30$ are being evaluated in clinical trials (50). A variety of BsAb formats $(>100)$ are available at present, from small diabodies to complex molecules larger than the conventional $\mathrm{IgG}$ used as therapeutic antibodies (48). These formats differ in size, arrangement, valency and flexibility, as well as in their distribution and pharmacokinetic properties, thus offering the possibility to select the best format for any desired application (48). BsAbs may be useful for cancer therapies as they can simultaneously activate and inhibit various mechanisms of action by directly targeting different molecules. For instance, they can target two antigens present on the surface of the same cell (51) or on two different cells, such as a tumor cell and an immune cell, which is currently the most developed strategy (52). Among the BsAbs against two membrane receptors, the RG7992/BFKB8488A antibody against FGFR1 and KLB, developed as a potential FGF21 mimetic, corresponds to a strategy similar to the one used for the anti-AMHRII-AKL BsAbs in the present study.

In the BsAbs developed in the present study, the relative affinity of the anti-AMHRII Fab (mean $\mathrm{EC}_{50}, 0.34 \mathrm{nM}$ ) compared with that of the anti-ALK Fab corresponded to a 1:100 ratio for the MAbs $2 \mathrm{C} 1,2 \mathrm{~F} 9$ and 3D7 $\left(\mathrm{EC}_{50}\right.$ from 26 to $\left.85 \mathrm{nM}\right)$ and to a 1:10 ratio for the $\mathrm{Mab} 3 \mathrm{H} 6\left(\mathrm{EC}_{50}, \sim 2 \mathrm{nM}\right)$. These affinity differences and the BsAb design ensured tumor specificity through AMHRII as the first step of the binding, and potential signaling through ALK2 or ALK3 binding. Notably, the BsAb with the highest affinity ratio and thus the lowest anti-ALK affinity (12G4-2F9) was the most efficient in vivo. In vivo, all BsAbs used in the present study reduced COV434-AMHRII tumor 
growth compared with that observed in the vehicle-treated group. The BsAb 12G4-2F9 was the most efficient with a T/C\% of $41 \%$ (59\% growth inhibition) and 68\% (32\% growth inhibition) compared with the vehicle and the BsAb targeting only AMHRII (12G4-CD5), respectively. The stronger antitumor effects of anti-AMHRII-ALK2 BsAbs compared with those of anti-AMHRII-ALK3 BsAbs was in line with the observation that ALK2 was mainly expressed at physiological endogenous AMH concentrations, whereas ALK3 was expressed at supraphysiological AMH concentrations. Accordingly, no exogenous AMH was added in the in vivo experiments. Pretreatment with AMH, as performed in our previous study of the AAV9-LR-AMH strategy (9), may favor ALK3 expression and increase the efficiency of the anti-AMHRII-ALK3 BsAbs. Alternatively, as ALK3 is mostly implicated in apoptosis induction, an anti-ALK3 MAb or an anti-AMHRII-ALK3 BsAb would have to be agonistic to reduce tumor growth. Agonist antibodies are rarely obtained unless specific and complex screening strategies are employed. Based on the present results, potential improvements of the anti-AMHRII-ALK2 BsAb will be considered, including new anti-ALK2 antibodies and other BsAb formats to compare them with the 12G4-2F9 BsAb.

In the present study, the effects of the newly developed BsAbs were compared in vivo, as these experiments may determine their therapeutic potential. Further detailed analyses of the effects of these BsAb on signaling will be the subject of subsequent studies. Even if the potential toxicity of the anti-AMHRII-ALK2 BsAb developed in the present study cannot be precisely analyzed in a murine model, the high affinity of the anti-AMHRII Fab (12G4) should limit it to AMHRII-expressing cells in the ovaries. From a medical point of view, these concerns are relatively minor, considering that the ovaries are typically surgically removed as part of the standard of care of ovarian cancers.

The original observation of the present study that ALK2 and ALK3 serve opposing roles in AMH signaling in ovarian cancer cells may improve the understanding of the involvement of this hormone in cancer and enable the development of novel anticancer strategies. The results of the present study constituted the proof of concept that BsAbs targeting AMHRII-ALK2 may inhibit tumor growth in ovarian cancer models, and may have enhanced efficacy compared with antibodies that target AMHRII alone. This is remarkable considering that these experiments were carried out in cells that overexpress AMHRII, since this overexpression may have limited the efficacy of the anti-ALK2 arm and of the AMHRII-ALK2 BsAb as a whole. The design of a potential clinical trial evaluating the anti-AMHRII-ALK2 BsAb will be based on the results of the current clinical trials performed in gynecological (NCT02978755) and colorectal (NCT03799731) cancers with the anti-AMHRII MAb (GM102, murlentamab). This strategy may offer an alternative to or complement the use of recombinant AMH to induce cancer cell apoptosis $(9,26)$.

\section{Acknowledgements}

The authors would like to thank Dr Christel Larbouret and Dr Muriel Brengues (Immunotargeting and Radiobiology in Oncology team at IRCM, Montpellier, France) for fruitful discussions and Dr Adeline Torro (IRCM animal facility manager, Montpellier, France) for support in in vivo experiments. The human COV434 and KGN cell lines were kind gifts from Dr Schrier (Department of Clinical Oncology, Leiden University Medical Center, Leiden, Netherlands) and Dr Yanase (Kyushu University, Fukuoka, Japan), respectively. The cDNA encoding full-length human AMHRII in the pCMV6 plasmid was gifted by Dr Teixeira (Pediatric Surgical Research Laboratories, Massachusetts General Hospital, Harvard Medical School, Boston, USA). The pIRES1-EGFP vector was gifted by Dr F Poulat (Institut de Génétique Humaine, CNRS, Montpellier, France).

\section{Funding}

This study was funded by the French National Research Agency under the program Investissements d' Avenir Grant Agreement LabEx MAbImprove (grant no. ANR-10-LABX-53), the Ligue Nationale Contre le Cancer, INSERM Transfert (Proof of Concept grant no. MISRII-MRI BsAbs) and the SIte de Recherche Intégrée sur le Cancer (SIRIC) Montpellier-Cancer (grant no. INCa-DGOS-Inserm 6045).

\section{Availability of data and materials}

The datasets used and/or analyzed during the current study are available from the corresponding author on reasonable request.

\section{Authors' contributions}

AP, MCha and TC conceived the study. MCha, VG, DPDB, MDC, KD, MChe, BR, MJ, INT, PM and SC performed the experiments. PEC provided the resources. AP and MCha confirm the authenticity of all raw data. AP wrote the original draft. AP, TC, DP, PEC, PM, INT, LG, DPDB, MCha, MDC, $\mathrm{VG}, \mathrm{MChe}, \mathrm{BR}, \mathrm{MJ}$ and SC reviewed and edited the manuscript. MCha designed the figures. AP supervised the study, was responsible for project administration and acquired funding. All authors read and approved the final manuscript.

\section{Ethics approval and consent to participate}

Ascites samples from patients with ovarian cancer were obtained from the Institut du Cancer de Montpellier (ICM) according to the French laws and after obtaining informed consent. All samples were retrieved from the ICM ovarian cancer clinical-biological database that had been approved by the independent Sud Méditerranée III Ethics Committee (reference no. 2016.09.06). All experimental protocols using these human samples were approved by the ICMComité de Recherche Translationnelle and were carried out in accordance with the French Guidelines and Regulations for Human Samples. All animal experiments were performed in compliance with the guidelines of the French government and INSERM regulations for experimental animal studies (agreement no. D34-172-27). All experimental protocols were approved by the Comité d'éthique en Expérimentation Animale Languedoc Roussillon.

\section{Patient consent for publication}

Not applicable. 


\section{Competing interests}

Maëva Chauvin, Myriam Chentouf, Pierre Martineau, André Pèlegrin and Bruno Robert are inventors in: Anti-Müllerian Inhibiting Substance Type I Receptor Antibodies And Uses Thereof. EP19306214.8 filed on 2019, September 27. All other authors confirm that they have no compssseting interests.

\section{References}

1. di Clemente N, Jamin SP, Lugovskoy A, Carmillo P, Ehrenfels C, Picard JY, Whitty A, Josso N, Pepinsky RB and Cate RL: Processing of anti-mullerian hormone regulates receptor activation by a mechanism distinct from TGF-beta. Mol Endocrinol 24 2193-2206, 2010.

2. Josso $\mathrm{N}$ and Clemente $\mathrm{N}$ : Transduction pathway of anti-Müllerian hormone, a sex-specific member of the TGF-beta family. Trends Endocrinol Metab 14: 91-97, 2003.

3. Masiakos PT, MacLaughlin DT, Maheswaran S, Teixeira J, Fuller AF Jr, Shah PC, Kehas DJ, Kenneally MK, Dombkowski DM, Ha TU, et al: Human ovarian cancer, cell lines, and primary ascites cells express the human Mullerian inhibiting substance (MIS) type II receptor, bind, and are responsive to MIS. Clin Cancer Res 5: 3488-3499, 1999.

4. Renaud EJ, MacLaughlin DT, Oliva E, Rueda BR and Donahoe PK: Endometrial cancer is a receptor-mediated target for Mullerian Inhibiting Substance. Proc Natl Acad Sci USA 102: 111-116, 2005.

5. Bakkum-Gamez JN, Aletti G, Lewis KA, Keeney GL, Thomas BM, Navarro-Teulon I and Cliby WA: Müllerian inhibiting substance type II receptor (MISIIR): A novel, tissue-specific target expressed by gynecologic cancers. Gynecol Oncol 108: 141-148, 2008.

6. Wei X, Dombkowski D, Meirelles K, Pieretti-Vanmarcke R, Szotek PP, Chang HL, Preffer FI, Mueller PR, Teixeira J, MacLaughlin DT, et al: Mullerian inhibiting substance preferentially inhibits stem/progenitors in human ovarian cancer cell lines compared with chemotherapeutics. Proc Natl Acad Sci USA 107: 18874-18879, 2010

7. Anttonen M, Färkkilä A, Tauriala H, Kauppinen M, Maclaughlin DT, Unkila-Kallio L, Bützow R and Heikinheimo M: Anti-Müllerian hormone inhibits growth of AMH type II receptor-positive human ovarian granulosa cell tumor cells by activating apoptosis. Lab Invest 91: 1605-1614, 2011.

8. Meirelles K, Benedict LA, Dombkowski D, Pepin D, Preffer FI, Teixeira J, Tanwar PS, Young RH, MacLaughlin DT, Donahoe PK, et al: Human ovarian cancer stem/progenitor cells are stimulated by doxorubicin but inhibited by Mullerian inhibiting substance. Proc Natl Acad Sci USA 109: 2358-2363, 2012.

9. Pépin D, Sosulski A, Zhang L, Wang D, Vathipadiekal V, Hendren K, Coletti CM, Yu A, Castro CM, Birrer MJ, et al: AAV9 delivering a modified human Mullerian inhibiting substance as a gene therapy in patient-derived xenografts of ovarian cancer. Proc Natl Acad Sci USA 112: E4418-E4427, 2015.

10. Kim JH, MacLaughlin DT and Donahoe PK: Müllerian inhibiting substance/anti-Müllerian hormone: A novel treatment for gynecologic tumors. Obstet Gynecol Sci 57: 343-357, 2014

11. Salhi I, Cambon-Roques S, Lamarre I, Laune D, Molina F, Pugnière M, Pourquier D, Gutowski M, Picard JY, Xavier F, et al: The anti-Müllerian hormone type II receptor: Insights into the binding domains recognized by a monoclonal antibody and the natural ligand. Biochem J 379: 785-793, 2004.

12. Yuan QA, Simmons HH, Robinson MK, Russeva M, Marasco WA and Adams GP: Development of engineered antibodies specific for the Müllerian inhibiting substance type II receptor: A promising candidate for targeted therapy of ovarian cancer. Mol Cancer Ther 5: 2096-2105, 2006.

13. Yuan QA, Robinson MK, Simmons HH, Russeva $M$ and Adams GP: Isolation of anti-MISIIR scFv molecules from a phage display library by cell sorter biopanning. Cancer Immunol Immunother 57: 367-378, 2008.

14. Bougherara H, Némati F, Nicolas A, Massonnet G, Pugnière M, Ngô C, Le Frère-Belda MA, Leary A, Alexandre J, Meseure D, et al: The humanized anti-human AMHRII mAb 3C23K exerts an anti-tumor activity against human ovarian cancer through tumor-associated macrophages. Oncotarget 8: 99950-99965, 2017.
15. Estupina P, Fontayne A, Barret J-M, Kersual N, Dubreuil O, Le Blay M, Pichard A, Jarlier M, Pugnière M, Chauvin M, et al: The anti-tumor efficacy of $3 \mathrm{C} 23 \mathrm{~K}$, a glyco-engineered humanized anti-MISRII antibody, in an ovarian cancer model is mainly mediated by engagement of immune effector cells. Oncotarget 8: 37061-37079, 2017.

16. Gill SE, Zhang Q, Keeney GL, Cliby WA and Weroha SJ: Investigation of factors affecting the efficacy of $3 \mathrm{C} 23 \mathrm{~K}$, a human monoclonal antibody targeting MISIIR. Oncotarget 8: 85214-85223, 2017.

17. Kersual N, Garambois V, Chardès T, Pouget JP, Salhi I, Bascoul-MolleviC, Bibeau F, Busson M, Vié H, Clémenceau B, et al: The human Müllerian inhibiting substance type II receptor as immunotherapy target for ovarian cancer. Validation using the mAb 12G4. MAbs 6: 1314-1326, 2014.

18. Belville C, Jamin SP, Picard JY, Josso N and di Clemente N: Role of type I receptors for anti-Müllerian hormone in the SMAT-1 Sertoli cell line. Oncogene 24: 4984-4992, 2005.

19. Clarke TR, Hoshiya Y, Yi SE, Liu X, Lyons KM and Donahoe PK: Müllerian inhibiting substance signaling uses a bone morphogenetic protein (BMP)-like pathway mediated by ALK2 and induces SMAD6 expression. Mol Endocrinol 15: 946-959, 2001.

20. Josso N, Racine C, di Clemente N, Rey R and Xavier F: The role of anti-Müllerian hormone in gonadal development. Mol Cell Endocrinol 145: 3-7, 1998.

21. Orvis GD, Jamin SP, Kwan KM, Mishina Y, Kaartinen VM, Huang S, Roberts AB, Umans L, Huylebroeck D, Zwijsen A, et al: Functional redundancy of TGF-beta family type I receptors and receptor-Smads in mediating anti-Mullerian hormone-induced Mullerian duct regression in the mouse. Biol Reprod 78: 994-1001, 2008.

22. Sèdes L, Leclerc A, Moindjie H, Cate RL, Picard JY, di Clemente N and Jamin SP: Anti-Müllerian hormone recruits BMPR-IA in immature granulosa cells. PLoS One 8: e81551, 2013.

23. Visser JA, Olaso R, Verhoef-Post M, Kramer P, Themmen AP and Ingraham HA: The serine/threonine transmembrane receptor ALK2 mediates Müllerian inhibiting substance signaling. Mol Endocrinol 15: 936-945, 2001.

24. Zhan Y, Fujino A, MacLaughlin DT, Manganaro TF, Szotek PP, Arango NA, Teixeira J and Donahoe PK: Müllerian inhibiting substance regulates its receptor/SMAD signaling and causes mesenchymal transition of the coelomic epithelial cells early in Müllerian duct regression. Development 133: 2359-2369, 2006.

25. Basal E, Ayeni T, Zhang Q, Langstraat C, Donahoe PK, Pepin D, Yin X, Leof E and Cliby W: Patterns of Müllerian inhibiting substance type II and candidate type I receptors in epithelial ovarian cancer. Curr Mol Med 16: 222-231, 2016.

26. Pépin D, Hoang M, Nicolaou F, Hendren K, Benedict LA, Al-Moujahed A, Sosulski A, Marmalidou A, Vavvas D and Donahoe PK: An albumin leader sequence coupled with a cleavage site modification enhances the yield of recombinant C-terminal Mullerian Inhibiting Substance. Technology (Singap) 1: 63-71, 2013.

27. Pépin D: Modified mullerian inhibiting substance (mis) proteins and uses thereof for the treatment of diseases. WO2014/164891, 2014.

28. Wilson CA, di Clemente N, Ehrenfels C, Pepinsky RB, Josso N, Vigier B and Cate RL: Mullerian inhibiting substance requires its $\mathrm{N}$-terminal domain for maintenance of biological activity, a novel finding within the transforming growth factor-beta superfamily. Mol Endocrinol 7: 247-257, 1993.

29. Cate RL, Mattaliano RJ, Hession C, Tizard R, Farber NM, Cheung A, Ninfa EG, Frey AZ, Gash DJ, Chow EP, et al: Isolation of the bovine and human genes for Müllerian inhibiting substance and expression of the human gene in animal cells. Cell 45: 685-698, 1986.

30. Philibert P, Stoessel A, Wang W, Sibler AP, Bec N, Larroque C, Saven JG, Courtête J, Weiss E and Martineau P: A focused antibody library for selecting scFvs expressed at high levels in the cytoplasm. BMC Biotechnol 7: 81, 2007.

31. Robin G and Martineau P: Synthetic customized scFv libraries. Methods Mol Biol 907: 109-122, 2012.

32. Golay J, Choblet S, Iwaszkiewicz J, Cérutti P, Ozil A, Loisel S, Pugnière M, Ubiali G, Zoete V, Michielin O, et al: Design and validation of a novel generic platform for the production of tetravalent IgG1-like bispecific antibodies. J Immunol 196: 3199-3211, 2016.

33. Kadouche J, Mach JP, Michielin O, Zoete V, Iwaszkiewicz J, Cerutti M, Choblet S and Golay J: Multispecific Antibodies. Patent WO2013005194. Filed July 6, 2012; issued January 10, 2013. 
34. Duke GM, Hoffman MA and Palmenberg AC: Sequence and structural elements that contribute to efficient encephalomyocarditis virus RNA translation. J Virol 66: 1602-1609, 1992.

35. Loisel S, André PA, Golay J, Buchegger F, Kadouche J, Cérutti M, Bologna L, Kosinski M, Viertl D, Delaloye AB, et al: Antitumour effects of single or combined monoclonal antibodies directed against membrane antigens expressed by human B cells leukaemia. Mol Cancer 10: 42, 2011.

36. Chan-Penebre E, Armstrong K, Drew A, Grassian AR, Feldman I, Knutson SK, Kuplast-Barr K, Roche M, Campbell J, Ho P, et al: Selective killing of SMARCA2- and SMARCA4-deficient small cell carcinoma of the ovary, hypercalcemic type cells by inhibition of EZH2: In vitro and in vivo preclinical models. Mol Cancer Ther 16: 850-860, 2017.

37. Zhang H, Vollmer M, De Geyter M, Litzistorf Y, Ladewig A, Dürrenberger M, Guggenheim R, Miny P, Holzgreve W and De Geyter C: Characterization of an immortalized human granulosa cell line (COV434). Mol Hum Reprod 6: 146-153, 2000.

38. Nishi Y, Yanase T, Mu Y, Oba K, Ichino I, Saito M, Nomura M, Mukasa C, Okabe T, Goto K, et al: Establishment and characterization of a steroidogenic human granulosa-like tumor cell line, $\mathrm{KGN}$, that expresses functional follicle-stimulating hormone receptor. Endocrinology 142: 437-445, 2001.

39. O Donnell RL, McCormick A, Mukhopadhyay A, Woodhouse LC, Moat M, Grundy A, Dixon M, Kaufman A, Soohoo S, Elattar A, et al: The use of ovarian cancer cells from patients undergoing surgery to generate primary cultures capable of undergoing functional analysis. PLoS One 9: e90604, 2014.

40. Chung YJ, Kim HJ, Park SH, Yoon JH, Kim MR, Nam SW, MacLaughlin DT, Donahoe PK and Kim JH: Transcriptome analysis reveals that Müllerian inhibiting substance regulates signaling pathways that contribute to endometrial carcinogenesis. Int J Oncol 46: 2039-2046, 2015.

41. Beck TN, Korobeynikov VA, Kudinov AE, Georgopoulos R, Solanki NR, Andrews-Hoke M, Kistner TM, Pépin D, Donahoe PK, Nicolas E, et al: Anti-Müllerian hormone signaling regulates epithelial plasticity and chemoresistance in lung cancer. Cell Rep 16: 657-671, 2016.
42. Köhler G, Howe SC and Milstein C: Fusion between immunoglobulin-secreting and nonsecreting myeloma cell lines. Eur J Immunol 6: 292-295, 1976.

43. Zhang YE: Non-Smad signaling pathways of the TGF- $\beta$ family. Cold Spring Harb Perspect Biol 9: 9, 2017.

44. Horbelt D, Denkis A and Knaus P: A portrait of transforming growth factor $\beta$ superfamily signalling: Background matters. Int J Biochem Cell Biol 44: 469-474, 2012.

45. Mazumder S, Johnson JM, Swank V, Dvorina N, Martelli E, Ko J and Tuohy VK: Primary immunoprevention of epithelial ovarian carcinoma by vaccination against the extracellular Domain of anti-Müllerian hormone receptor II. Cancer Prev Res (Phila) 10: 612-624, 2017.

46. Song JY, Chen KY, Kim SY, Kim MR, Ryu KS, Cha JH, Kang CS, MacLaughlin DT and Kim JH: The expression of Müllerian inhibiting substance/anti-Müllerian hormone type II receptor protein and mRNA in benign, borderline and malignant ovarian neoplasia. Int J Oncol 34: 1583-1591, 2009.

47. Uhlén M, Fagerberg L, Hallström BM, Lindskog C, Oksvold P, Mardinoglu A, Sivertsson A., Kampf C, Sjöstedt E, Asplund A, et al: Proteomics. Tissue-based map of the human proteome. Science 347: 1260419, 2015.

48. Brinkmann U and Kontermann RE: The making of bispecific antibodies. MAbs 9: 182-212, 2017.

49. Carter PJ and Lazar GA: Next generation antibody drugs: Pursuit of the 'high-hanging fruit'. Nat Rev Drug Discov 17: 197-223, 2018.

50. Labrijn AF, Janmaat ML, Reichert JM and Parren PW: Bispecific antibodies: A mechanistic review of the pipeline. Nat Rev Drug Discov 18: 585-608, 2019.

51. Kontermann RE: Dual targeting strategies with bispecific antibodies. MAbs 4: 182-197, 2012

52. Spiess C, Zhai Q and Carter PJ: Alternative molecular formats and therapeutic applications for bispecific antibodies. Mol Immunol 67: 95-106, 2015. International (CC BY-NC-ND 4.0) License. 